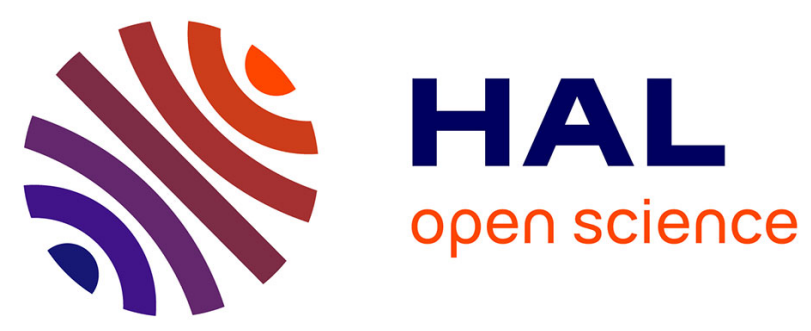

\title{
Prediction and Diagnosis of the Motion and Rapid Intensification of Typhoon Sinlaku during Tropical Cyclone Structure Experiment 2008 (TCS08)
}

Marie-Dominique Leroux, Noel E. Davidson, Yimin Ma, Jeffrey D. Kepert

\section{- To cite this version:}

Marie-Dominique Leroux, Noel E. Davidson, Yimin Ma, Jeffrey D. Kepert. Prediction and Diagnosis of the Motion and Rapid Intensification of Typhoon Sinlaku during Tropical Cyclone Structure Experiment 2008 (TCS08). Monthly Weather Review, 2013, 141 (5), pp.1413-1436. 10.1175/MWRD-11-00346.1 . hal-01103241

\section{HAL Id: hal-01103241 \\ https://hal.science/hal-01103241}

Submitted on 14 Jan 2015

HAL is a multi-disciplinary open access archive for the deposit and dissemination of scientific research documents, whether they are published or not. The documents may come from teaching and research institutions in France or abroad, or from public or private research centers.
L'archive ouverte pluridisciplinaire HAL, est destinée au dépôt et à la diffusion de documents scientifiques de niveau recherche, publiés ou non, émanant des établissements d'enseignement et de recherche français ou étrangers, des laboratoires publics ou privés. 


\title{
Prediction and Diagnosis of the Motion and Rapid Intensification of Typhoon Sinlaku during Tropical Cyclone Structure Experiment 2008 (TCS08)
}

\author{
MARIE-DOMINIQUE LEROUX \\ Centre for Australian Weather and Climate Research, Bureau of Meteorology, Melbourne, Australia, and Laboratoire \\ de l'Atmosphère et des Cyclones, Unité mixte CNRS-Météo-France-Université de La Réunion, La Réunion, France \\ Noel E. Davidson, Yimin Ma, And JefFrey D. KePert \\ Centre for Australian Weather and Climate Research, Bureau of Meteorology, Melbourne, Australia
}

(Manuscript received 30 November 2011, in final form 8 November 2012)

\begin{abstract}
The impact of initial structure on storm evolution is examined for the case of a tropical storm entering rapid intensification. At the onset of rapid intensification, satellite cloud signatures suggest that the structural organization of Typhoon Sinlaku (2008) was dominated by a primary band of convection present at outer radii. The development of the eyewall subsequently occurred within this band of deep convection.

Numerical forecasts of Sinlaku are initialized at $15-$ and 5-km resolution using a broad range of vortex scales, at a time when the storm was still weak and its structure not clearly defined. Evidence is presented that beta propagation played a key role in changing the storm's motion under weak environmental steering. It is found that the track forecast improves over the period when beta propagation is prominent if the vortex is initialized with a large radius of maximum wind (RMW), corresponding with the primary outer cloud band. The initial vortex structure is also suggested to play a critical role in the pathway to rapid intensification, and in the formation of the eyewall for the defined environmental forcing. With an initially large RMW, the forecast captures the evolution of structure and intensity more skillfully. Eyewall formation inside the primary outer convective band for the weak storm is illustrated and some possible dynamical interpretations are discussed.
\end{abstract}

\section{Introduction}

The capability of numerical atmospheric models to provide skillful forecasts relies on the accuracy of the initial state (Davidson and Ma 2012). This is particularly true for tropical cyclones (TCs; Kurihara et al. 1995). Unfortunately, over the data-sparse oceanic regions, conventional observations are insufficient to adequately analyze the structure or location of a cyclone inner core. Therefore, bogusing techniques (or "vortex specifications") have been developed to improve the initialization of TCs (e.g., Kurihara et al. 1993; Kwon et al. 2002). They are a key aspect for forecasting the track, intensity, and structure of TCs (Davidson et al. 2006), together with the specification of the initial large-scale environment surrounding the TC (Komaromi et al. 2011), and

Corresponding author address: Marie-Dominique Leroux, MétéoFrance DIRRE, Cellule Recherche Cyclones, BP4, 97491 Ste Clotilde, La Réunion, France.

E-mail: marie-dominique.leroux@meteo.fr prediction of its evolution by the model (Bender et al. 1993; Davidson et al. 2006). Recent TC initialization procedures have benefited from further improvements. They include vortex specification from Advance Microwave Sounding Unit (AMSU-A) data (Zhu et al. 2002), variational assimilation of satellite-derived data (Xiao et al. 2000; Montroty et al. 2008; Liu and Li 2010), variational bogus data assimilation (Zou and Xiao 2000; $\mathrm{Pu}$ and Braun 2001; Wu et al. 2006), and vortex initialization based on the ensemble Kalman filter (e.g., Wu et al. 2010).

The idealized bogusing approach consists of inserting a synthetic three-dimensional vortex into the model analysis. The bogus is constructed to fit real-time estimates of storm size and intensity. A common scale for vortex size is the radius of maximum wind (RMW), while prevailing measures of storm size include the radius of gale-force wind (R34) and the radius of the outer closed isobar (ROCI). A number of methods based on satellite sensors have been developed to retrieve such types of information (Dvorak 1975; Mueller et al. 2006; 
Knaff and DeMaria 2006). However, there are still large uncertainties in the estimates of structure parameters, particularly for weak storms.

The large diversity of storm structure was highlighted by Samsury and Zipser (1995) with aircraft wind profiles: secondary wind maxima are sometimes present in TCs within outer convective rainbands and vary in position and strength. Now that assimilation of bogus data has been shown to have a positive impact on TC intensity prediction for many numerical models in most situations, details in the structure of the idealized bogus need more attention from research and development. This is obvious for weak storms, or for storms undergoing a secondary eyewall cycle at the initialization time. An important result is given by $\mathrm{Xu}$ and Wang (2010), who showed that simulated inner-core size is largely determined by initial vortex size. Semi-idealized simulations of a suite of modified Rankine vortices defined by RMW and wind profile decay factors suggest that improved initialization in the outer wind region might affect intensity and track forecast (Cao et al. 2011). In addition Ma et al. (2012) described the impact of vortex structure on TC prediction during some events. They also noted that (i) the model retains the general characteristics of the initial vortex and (ii) the pathway to intensification can be sensitive to initial vortex structure. Questions then follow: How can the structural characteristics of a storm influence the pathway to its intensification for the same environmental forcing? Are there instances when storm structure plays an important role in the motion?

Storm tracks are mainly driven by environmental steering and by the beta effect (Holland 1983; Chan and Williams 1987). Nondivergent, barotropic model experiments with no basic current showed that horizontal advection of planetary vorticity by the symmetric vortex circulation produces an asymmetric circulation composed of an anticyclone east of the center, and a cyclone to the west (Fiorino and Elsberry 1989). These westeast-aligned $\beta$ gyres, typically centered $600-700 \mathrm{~km}$ away from the cyclone, generate a nearly uniform broadscale southerly flow across the TC. Nonlinear advection of these gyres by the vortex flow subsequently twists the interior region between the gyres and orients the advective flow across the TC toward the northwest rather than poleward; as a result, more cyclonic vortices move more westward. The authors indicated that the storm is advected primarily by the flow between the gyres, which covers the area of significant cyclonic circulation. The northward component can spread out to $10^{\circ}$ (Carr and Elsberry 1992) whereas the westward twist of the gyres mostly occurs over the inner-core region of the storm (e.g., Fig. 2 of Carr and Elsberry 1992). The total northwestward propagation, also called "beta drift," was found to increase with both the maximum wind speed and the radius of maximum wind (Chan and Williams 1987), together with the outer-core wind speed (Carr and Elsberry 1997). In theory, the $\beta$-effect propagation can therefore contribute significantly to TC motion (by 1 to $3 \mathrm{~m} \mathrm{~s}^{-1}$ order of magnitude; Fiorino and Elsberry 1989), especially when environmental influences are small and when the storm is large. To adequately resolve the $\beta$ gyres associated with TCs moving in weak ambient flows, Reeder et al. (1991) showed that a $100-\mathrm{km}$ data network was required, which we have in this study (from in situ measurements during a field experiment).

Despite significant improvements in TC track forecasts over the past few decades (Franklin 2008), anticipating sudden intensity changes remains challenging. Kaplan and DeMaria (2003) defined rapid intensification (RI) for a system beyond the depression stage, when its maximum sustained surface winds increase by $30 \mathrm{kt}\left(15.4 \mathrm{~m} \mathrm{~s}^{-1}\right)$ in the course of $24 \mathrm{~h}$. The main factors influencing TC intensification are known to be ocean heat fluxes (Emanuel 1986; Shay et al. 2000; Lin et al. 2005) and environmental forcing (Molinari and Vollaro 1989; Hanley et al. 2001; Ritchie and Elsberry 2007; Davidson et al. 2008). Internal processes and asymmetries that modify the vortex structure have also been documented to explain TC intensity changes. They include concentric eyewall cycles (Willoughby 1990), vortex Rossby waves (Montgomery and Kallenbach 1997; Wang 2002), the dynamics of eyewall mesovortices and the mixing of potential vorticity in the TC core (Schubert et al. 1999; Kossin and Schubert 2001; Hendricks et al. 2009), as well as vortical hot towers (VHTs; Montgomery et al. 2006). Recently Nguyen et al. (2011) examined internal structure changes during the rapid intensification of Hurricane Katrina (2005) from high-resolution ensemble simulations. The innercore vortex appeared to vacillate between two distinct states characterized by a monotonic potential vorticity distribution with VHTs dominating at inner radii, or a ringlike structure. The mean circulation intensified rapidly when the potential vorticity anomalies associated with the VHTs were axisymmetrized to form the ring structure.

The present study investigates the sensitivity of track and intensity prediction to initial storm-size parameters for the case of Typhoon Sinlaku (2008), whose structure was not well defined at the onset of rapid intensification. This is an attempt to understand which structure parameters could be of potential importance in the subsequent development and movement of an initially weak storm. Sinlaku developed in the northwest Pacific during 
(a)

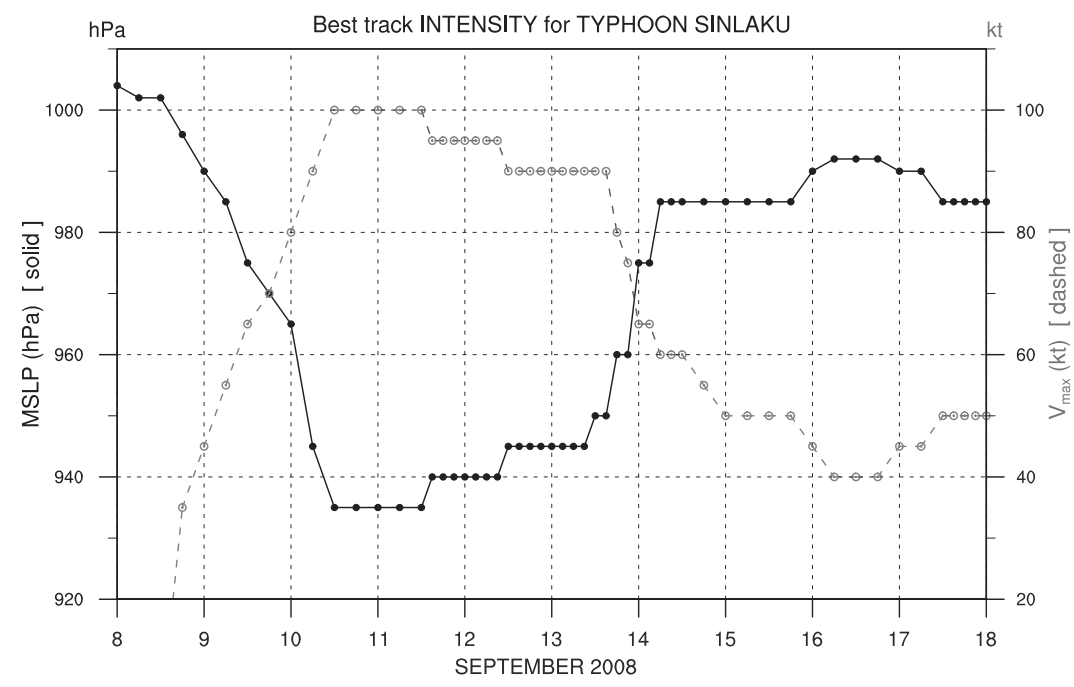

(b)

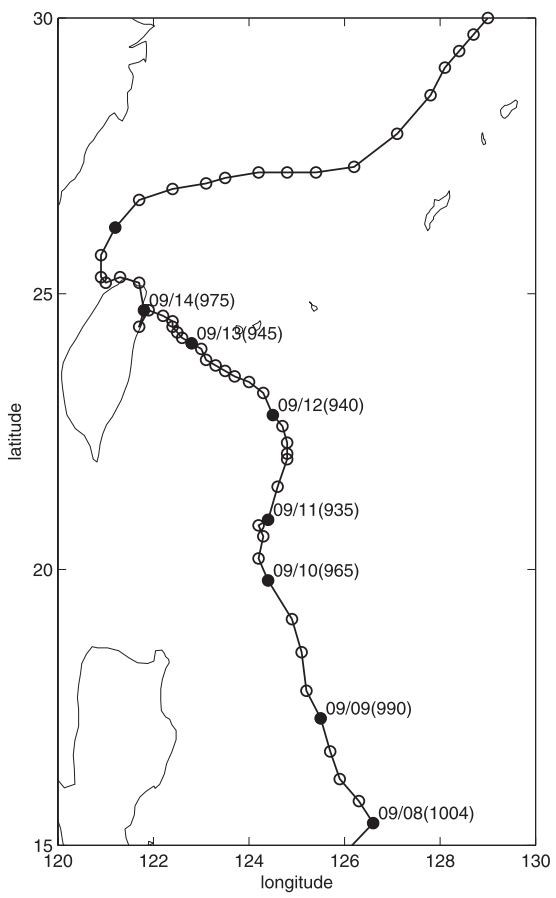

FIG. 1. Best-track intensity and location estimates from IBTrACS for Typhoon Sinlaku from 0000 UTC 8 Sep to 0000 UTC 18 Sep 2008 at 3- to 6-h intervals. (a) Intensity given by the central MSLP (hPa, solid line, left axis) and by the maximum wind speed (kt, dashed gray line, right axis). (b) Track of the storm center with central pressure at 0000 UTC of each day in parentheses.

the international campaign Tropical Cyclone Structure 2008 (TCS08; Elsberry et al. 2008). Our model initial and boundary conditions therefore benefit from an enhanced observational dataset expected to improve prediction of the large-scale environment. The paper is organized as follows: section 2 illustrates the observed evolution of Sinlaku during and right after RI (environment, intensification, structure, and track). Section 3 describes the setup for numerical sensitivity experiments on vortex initialization. Results on track prediction are presented and analyzed in section 4, while section 5 focuses on the prediction of intensity with complementary high-resolution experiments to investigate structure changes. Section 6 presents a summary and outlines possible future investigations.

\section{The observed evolution of Typhoon Sinlaku}

\section{a. A favorable environment for RI}

Figure 1 displays Sinlaku track and intensity estimates from the International Best Track Archive for Climate Stewardship (IBTrACS; Knapp et al. 2010). After the storm was named at 1800 UTC 8 September 2008 by the Japan Meteorological Agency, it rapidly intensified until 1200 UTC 10 September. A 42-h pressure fall of $61 \mathrm{hPa}$ from $996 \mathrm{hPa}$ was associated with RI (Fig. 1a). Maximum winds intensified from $35 \mathrm{kt}$ (18 $\mathrm{m} \mathrm{s}^{-1}$, tropical storm stage) to $100 \mathrm{kt}\left(51 \mathrm{~m} \mathrm{~s}^{-1}\right.$, typhoon stage).

From 9 to 12 September, large ocean heat content (not illustrated), enhanced poleward and equatorward outflow channels (not illustrated), as well as low vertical wind shear (Figs. 2a-d) are conducive to TC intensification. Wind analyses from the Australian Community Climate and Earth-System Simulator (ACCESS-G; Puri et al. 2010) show that environmental conditions are also favorable at $850 \mathrm{hPa}$ (Fig. 3, left panels). The monsoon westerly flow accelerates and extends from over the Bay of Bengal into the northwest Pacific (gray shading), and monsoon gyres (Chen et al. 2008) can be seen. This is beneficial for generating and maintaining large typhoons in the northwest Pacific (Lee et al. 2010). The contribution of the monsoon amplification to the rapid intensification of Sinlaku will be reported in a companion study.

\section{b. Track analysis}

From 10 to 12 September, Sinlaku is situated in between two large deep-layer anticyclones located over China and the northwest Pacific (Figs. 3c,e). The lack of 

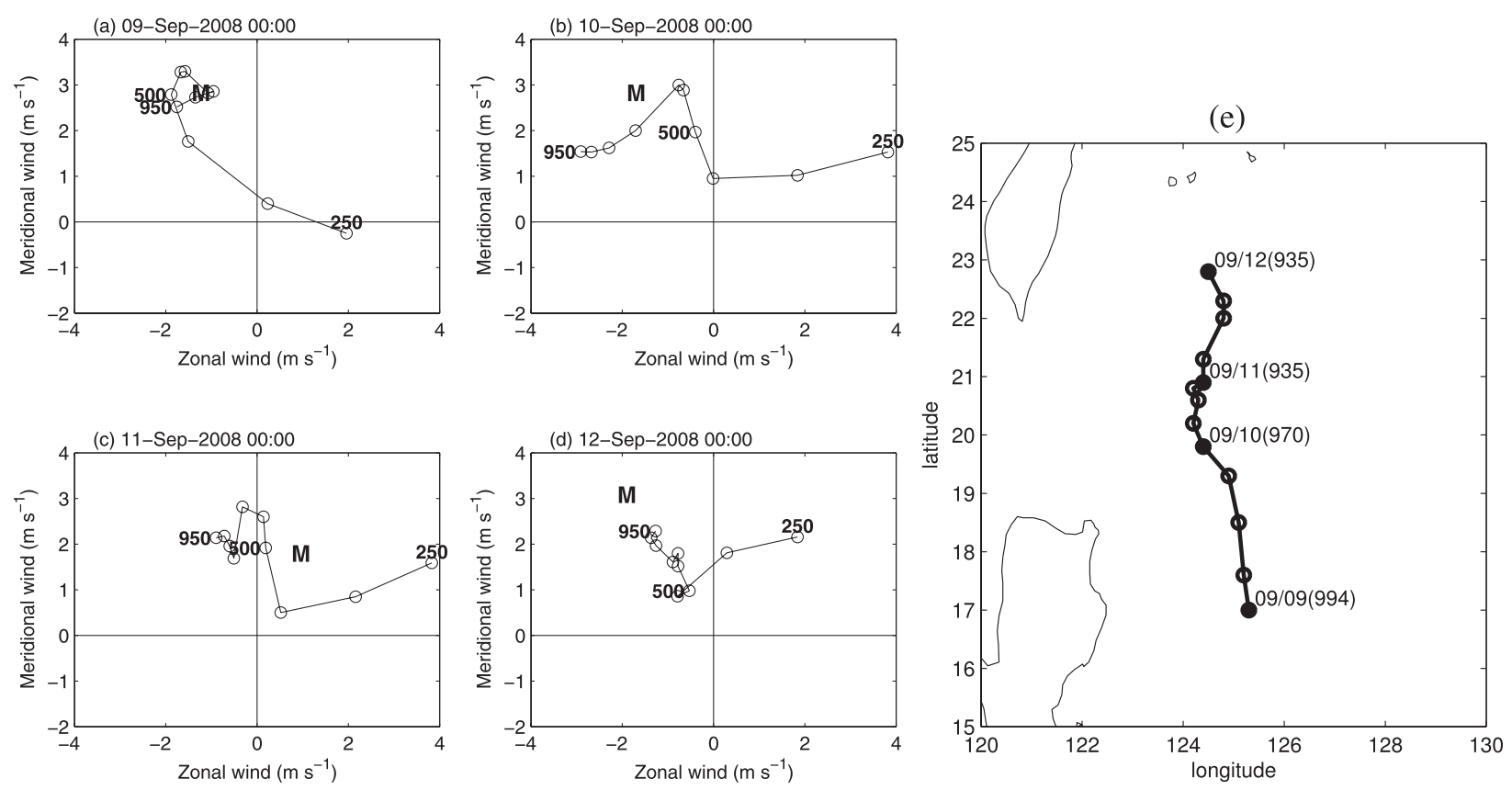

FIG. 2. (a)-(d) Environmental hodographs for Sinlaku showing wind shear derived from ACCESS-G analyses from 0000 UTC 9 Sep to 0000 UTC 12 Sep 2008 at 24-h intervals. The motion of Typhoon Sinlaku (from IBTrACS) is indicated by the M label. Winds are averaged over a 200-800-km annulus centered on the storm at each pressure level from 950 to $250 \mathrm{hPa}$; heights shown are hectopascal levels. (e) As in Fig. 1b, but for the period 9-12 Sep 2008.

a dominant steering flow results in a winding course of the storm (Fig. 2e). Hodographs in Fig. 2 show winds averaged over a $200-800-\mathrm{km}$ storm-centered annulus, without removing the storm vortex, following Kaplan and DeMaria (2003). A smaller radius such as $500 \mathrm{~km}$ is regarded as inapplicable for this large storm (ROCI around $400 \mathrm{~km}$ ). The environmental steering estimated over a $200-800-\mathrm{km}$ annulus excludes the vortex symmetric circulation but is somewhat contaminated by the inclusion of a significant portion of the meridional flow between the hypothetical gyres (Carr and Elsberry 1992, see their Fig. 3 and related discussion).

From 9 to 11 September, the observed storm motion is consistent with the mean steering flow in the 850250-hPa layer (Figs. 2a-c). The east-northeastward steering current at upper levels increases from 9 to 10 September, as the storm moves farther north under the consolidating upper-level anticyclone. At low levels, the monsoon westerlies strengthen from 10 to 11 September while easterlies north of the system weaken (Figs. 3c,e). Therefore the low-level steering component to the west decreases (Fig. 2c), which induces a slight eastward shift in the storm's zonal motion (Fig. 2e). Track direction starts shifting again to the north-northwest by 1200 UTC 11 September (Fig. 2e). However, the largescale steering flow has decreased and suggests a nearly pure $1.5 \mathrm{~m} \mathrm{~s}^{-1}$ northward translation of the storm on
12 September (Fig. 2d). It departs significantly from the observed $3.6 \mathrm{~m} \mathrm{~s}^{-1}$ northwestward motion that is larger than the environmental wind at any level (Fig. 2d).

A dynamical analysis of vortex motion is performed based on analytic theories conducted on barotropic vortices (Fiorino and Elsberry 1989; Chan and Williams 1987; Carr and Elsberry 1997). Even when Sinlaku is weak, the vortex is well represented in the analyses (Fig. 3, left panels). It indicates that experimental observations (such as scatterometer data) have sufficiently enriched the model background field to investigate the $\beta$ gyres (Reeder et al. 1991). The wavenumber-1 asymmetry of the total streamfunction averaged over the 850-700-hPa layer is extracted using a Fourier analysis (Fig. 3, right panels). Considering the weak steering current, the large-scale flow is not extracted [a possible extraction is described in Weber and Smith (1995)]. Therefore, the asymmetric field contains both the basic state plus the nonlinear interaction of the storm with its environment (the prospective $\beta$ gyres).

At 0000 UTC 10 September, the vortex develops a wavenumber- 1 asymmetry consisting of a pair of largescale counter-rotating gyres (Fig. 3d) that were not seen $24 \mathrm{~h}$ earlier (Fig. 3b). They are oriented southwestnortheast and centered about $600 \mathrm{~km}$ away from Sinlaku. At 0000 UTC 11 September, Sinlaku has reached maximum intensity and is undergoing an eyewall 
(a) 0000 UTC $09 \mathrm{Sep}$

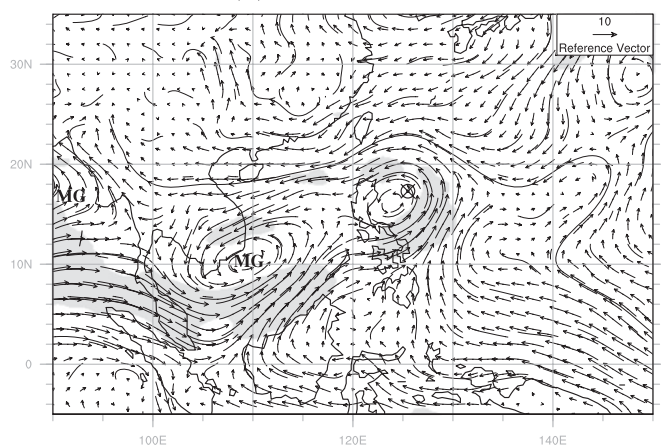

(c) $0000 \mathrm{UTC} 10 \mathrm{Sep}$

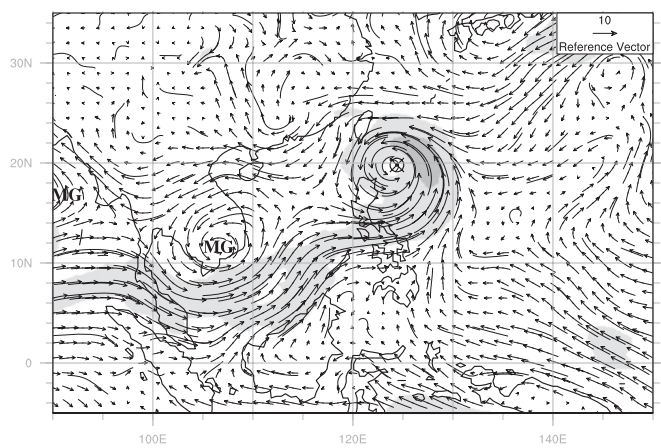

(e) 0000 UTC $11 \mathrm{Sep}$

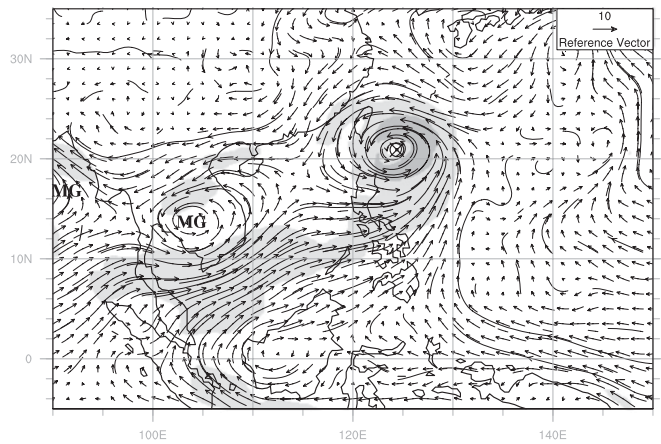

(g) 0000 UTC $12 \mathrm{sep}$

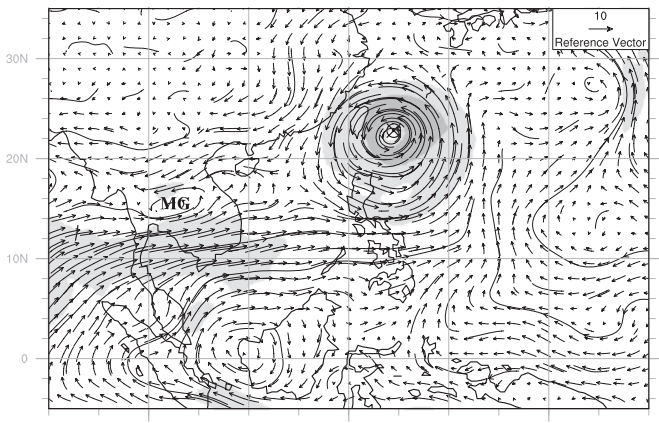

$140 \mathrm{~B}$
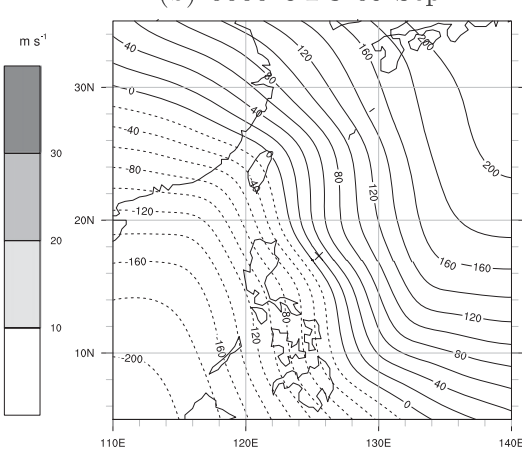

(d) 0000 UTC $10 \mathrm{Sep}$

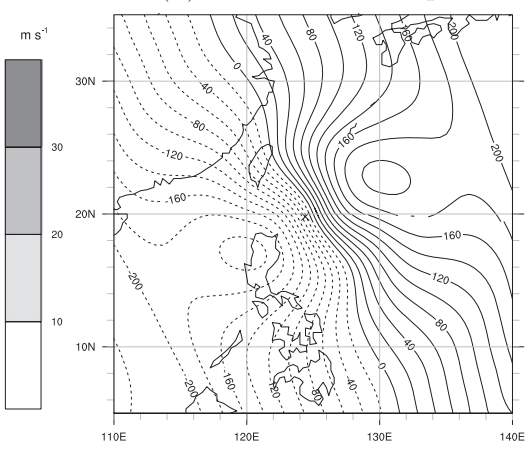

(f) 0000 UTC $11 \mathrm{Sep}$

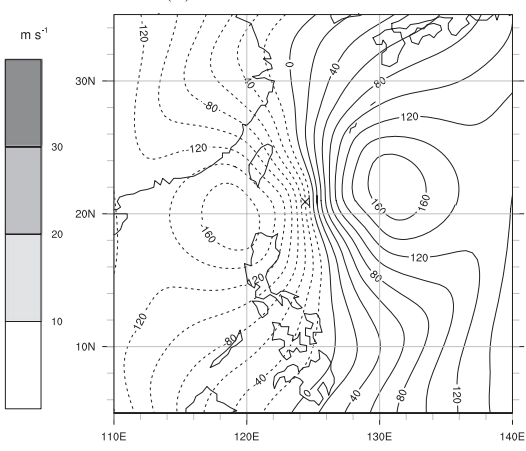

(h) 0000 UTC $12 \mathrm{sep}$

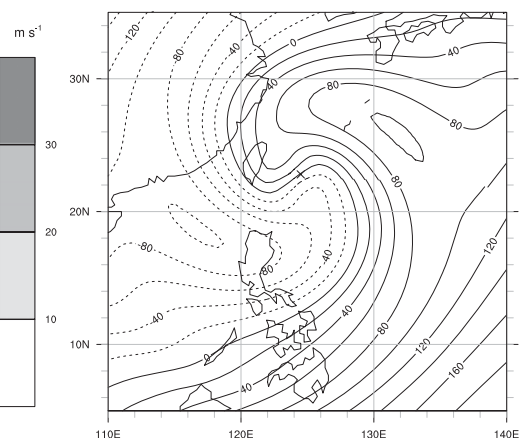

FIG. 3. ACCESS-G objective analysis from (top) 0000 UTC 9 Sep to (bottom) 0000 UTC 12 Sep 2008 at 24-h intervals of (a),(c),(e),(g) 850-hPa wind (shaded) and corresponding vectors (arrows) and (b),(d),(f),(h) the wavenumber-1 asymmetry of the 850-700-hPa layer mean streamfunction $(2 \times$ $10^{4} \mathrm{~m}^{2} \mathrm{~s}^{-1}$; positive, solid; negative, dotted). The contour interval is 20 from 0 to 200 and 50 from 200 to 300 . The location of Typhoon Sinlaku (from IBTrACS) is indicated by a crisscross $(\times)$ symbol. Monsoon gyres are indicated by MG labels. 
replacement cycle (see next paragraph). The scale of the vortex and the gyres, centered $700 \mathrm{~km}$ from the cyclone, increases, and the asymmetric flow across the vortex center is now directed toward the north-northwest (Fig. 3f). At 0000 UTC 12 September, the vortex continues expanding. Negative (positive) streamfunction anomalies oriented southwest (northeast) are still apparent (Fig. 3h) though highly distorted from the nonlinear interaction of Sinlaku with its environment (including the planetary vorticity). The distorting influence from the $\beta$ effect is greater as winds from the south (north) on the east (west) side of the vortex advect smaller (larger) earth vorticity values in the larger mature storm (Carr and Elsberry 1997).

Though embedded in the synoptic flow, the diagnosed gyres are found closer to the TC core than the low-level monsoon gyre to the southwest and the anticyclonic features to the east. Anomaly pairs translate with the TC over a 24-h period but keep an earth-fixed orientation (Franklin et al. 1996) and the appropriate location and orientation for model $\beta$ gyres of vortices in a quiescent environment. Such features are, therefore, likely to be the result of vortex-beta interaction. In any case, this may explain the significant departure of Sinlaku's motion from southerly steering at 0000 UTC 12 September (Fig. 2d). The respective contributions of the model and the observations in determining the occurrence of the $\beta$ gyres were not assessed. However, we believe the gyres existed in nature for Sinlaku and this assumption is supported by the storm's best track.

In conclusion, Sinlaku's observed motion change from the north-northeast to the north and finally to the northwest is attributed to changes in the environmental flow, and to the increasing influence of the $\beta$ propagation as environmental steering weakens and the structure and size of the vortex changes. Once the eyewall replacement cycle starts around 1200 UTC 10 September (see next paragraph), storm winds become strong enough at large radii for the $\beta$-effect propagation to increase (Carr and Elsberry 1997), reach a $2 \mathrm{~m} \mathrm{~s}^{-1}$ order of magnitude similar to the large-scale steering flow, and resist the eastward motion that is induced by the large-scale environment.

\section{c. The evolving structure of Sinlaku}

Passive microwave imagery (Fig. 4) outlines Sinlaku's evolving structure during RI and afterward. Both the Special Sensor Microwave Imager Sounder (SSMI/S) 91-GHz channel and the Advanced Microwave Scanning Radiometer (AMSR-E) 89-GHz channel images are selected to minimize temporal sampling issues. Their microwave channels are similar in resolution and frequency to the $85 \mathrm{GHz}$ on SSM/I. Ice scattering reveals areas of deep convection displayed in the red shades while dark blue areas correspond either to emission from land or from low-level clouds. Such imagery allows high-resolution mapping of eyewall(s) and rainbands that do not appear in visible and infrared data. Additional details about the TC structure are revealed by the $37-\mathrm{GHz}$ channel that can distinguish shallow convective rainbands, which appear as cyan, from deep convection, highlighted in pink (Fig. 4). The shallow rainband structure has been shown to be crucial in the development of initial periods of RI (Kieper 2008). Aircraft operations also sampled some structural parameters twice during the rapid intensification of Sinlaku. (Mission scientist reports from the U.S. Air Force Hurricane Hunter WC-130J are available at http:// catalog.eol.ucar.edu/tparc_2008/missions/index.html.)

At the beginning of RI, around 2200 and 2300 UTC 8 September, both 37- and 91-GHz images (Figs. 4a,b) indicate a primary band of convection (PBC) located $220 \mathrm{~km}$ away from a large circulation center, and a possible nascent eye. This band of precipitation appears very nearly as a closed ring and is composed of shallow (deep) convection in the northern (southern) region (Fig. 4a). A shift in core dynamics (Kieper 2008) occurs with the onset of rapid intensification (defined here as the period from 1800 UTC 8 September to 0000 UTC 9 September). Shallow convective precipitation develops in the inner region of Sinlaku (0910 UTC 9 September, Fig. 4d), inside of the PBC that dwells at an averaged $180-\mathrm{km}$ radius with heavier precipitation (Fig. 4e). Some $10 \mathrm{~h}$ later, the primary convective band is atrophying while deep convection is establishing in the inner ring that intensifies (Figs. 4f,g). This is similar to the general trend in structural organization of rapidly intensifying storms (Kieper 2008).

The aircraft mission around 0500 UTC 9 September reported a "ragged eyewall" (U.S. Air Force scientist report), visible in Fig. 4c. Havel (2009) identified a broad center from the radial distribution of surface and flightlevel winds: the wind distribution is highly asymmetric and the relative wind maxima are not well defined, located at $45 \mathrm{~km}$ in the eastern sector and out to $130 \mathrm{~km}$ in the southern quadrant.

The inner ring of intense precipitation consolidates to become a closed eyewall just before the completion of RI (0913 UTC 10 September, Fig. 4h). The apparent $1^{\circ}$ diameter of this narrow eyewall is confirmed by a second mission (from 0500 to 0830 UTC) that mentioned a "ragged but distinguishable nearly circular eyewall with radius of about $25 \mathrm{n} \mathrm{mi}(46 \mathrm{~km})$." The new outer spiraling bands visible in Fig. 4h start to merge afterward, resulting in an eyewall replacement cycle (Shapiro and Willoughby 1982; Willoughby et al. 1982). The cycle 
(a) $37 \mathrm{GHz} 082200$

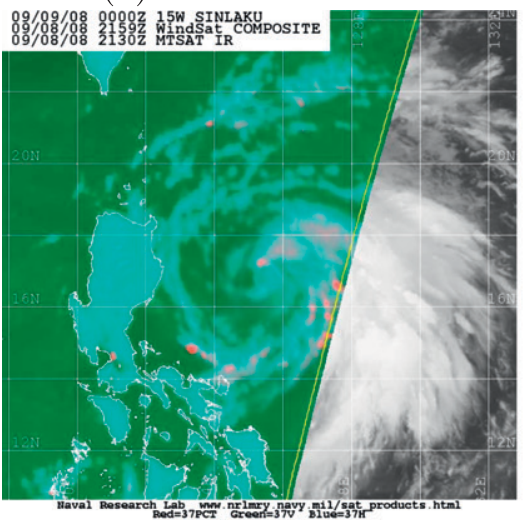

(d) $37 \mathrm{GHz} 090900$

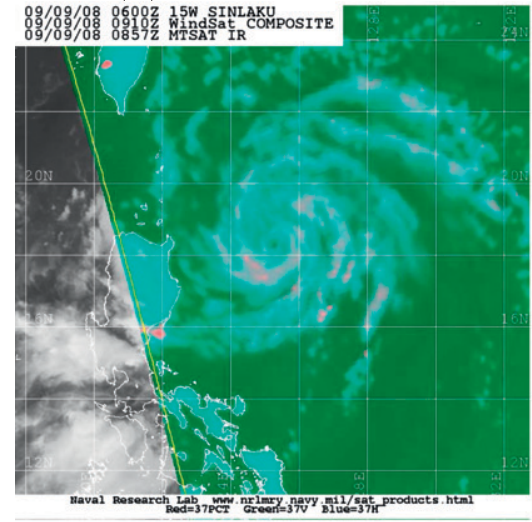

(g) $37 \mathrm{GHz} 092130$

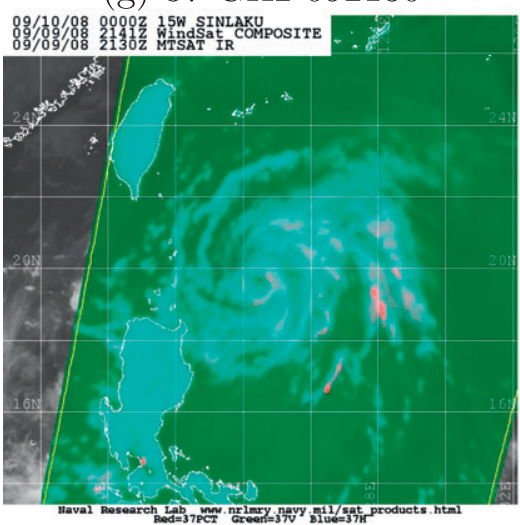

(b) $91 \mathrm{GHz} 082300$

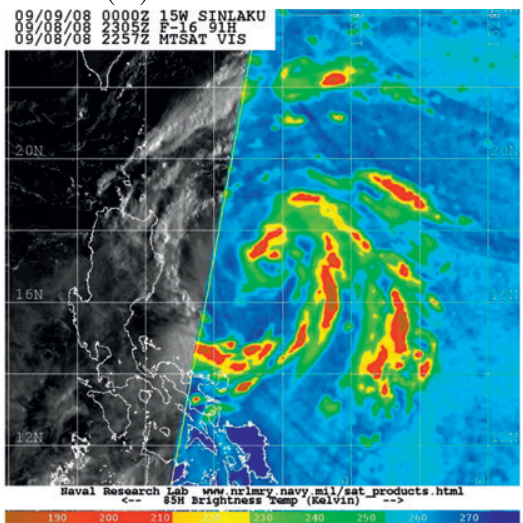

(e) $91 \mathrm{GHz} 090930$

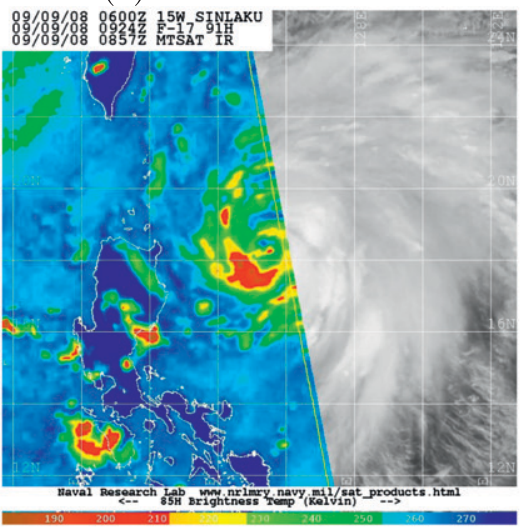

(h) $91 \mathrm{GHz} 100900$

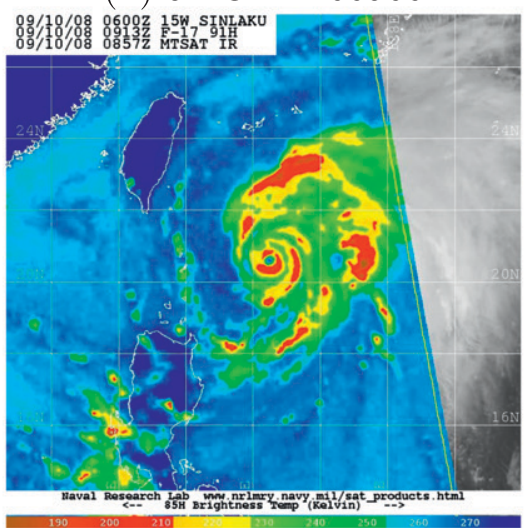

(c) $89 \mathrm{GHz} 090500$

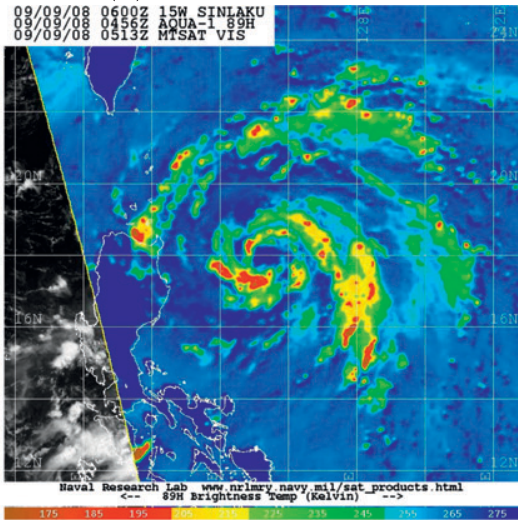

(f) $89 \mathrm{GHz} 091700$

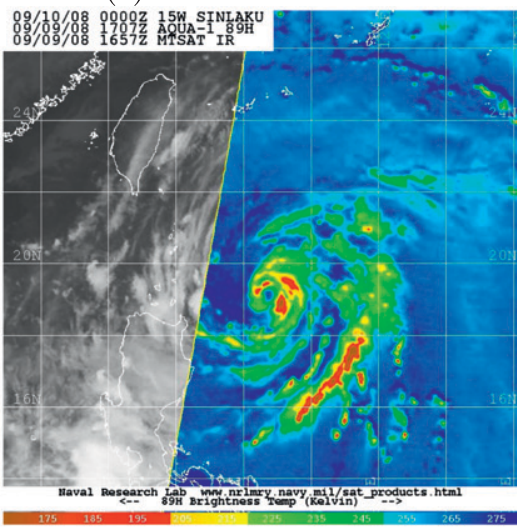

(i) $91 \mathrm{GHz} 110900$

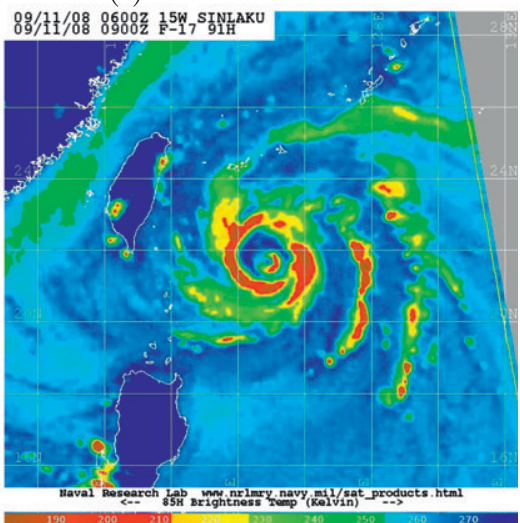

FIG. 4. Microwave imagery from the SSMIS 91-GHz, AMSR-E 89-GHz, and WindSat 37-GHz channels showing the horizontal distribution of the brightness temperature (K) around Typhoon Sinlaku at the approximate times: (a) 2200 UTC, (b) 2300 UTC 8 Sep; (c) 0500, (d) 0900, (e) 0930, (f) 1700, and (g) 2130 UTC 9 Sep; (h) 0900 UTC 10 Sep; and (i) 0900 UTC 11 Sep 2008. The microwave images are overlaid on Multifunctional Transport Satellite (MTSAT) visible or infrared images around the same time. Grid lines are drawn every $2^{\circ}$ latitude-longitude. Images courtesy of the Naval Research Laboratory. (Source: http://www.nrlmry.navy.mil/tc_pages/tc_home.html.)

starts right after RI (near 1200 UTC 10 September), when the surrounding ring of convection takes shape, and ends around 2200 UTC 11 September, once the inner eyewall has collapsed entirely (and the remaining thick eyewall only contracts another few kilometers). Two nearly concentric eyewalls are visible at 0900 UTC 11 September, extending to about 20 and $100 \mathrm{~km}$, respectively (Fig. 4i). 


\section{d. An uncertainty for structure parameters at the onset of RI}

According to the cloud signatures identified in Figs. $4 a, b$, the structural organization of the weak storm (from 35 to $\left.45 \mathrm{kt}, 1 \mathrm{kt}=0.5144 \mathrm{~m} \mathrm{~s}^{-1}\right)$ at the initial period of rapid intensification (from 1800 UTC 8 September to 0000 UTC 9 September) may be dominated by the $\mathrm{PBC}$ present at outer radii $(220 \mathrm{~km})$. A distant secondary wind maximum was depicted by the Quick Scatterometer (QuikSCAT) data at 2100 UTC, at least in the northern quadrant of the PBC (http://tparc.mri-jma.go. jp/qscat/figures/200809/qs.08090821.png). Also, early on 9 September the WC-130 mission witnessed that the circulation was still broad, with winds spread out to large outer radii and the wind maximum not well defined (Havel 2009). There is, therefore, an uncertainty for the radius of maximum wind at 0000 UTC 9 September; it is inferred that a secondary wind maximum could have been associated with the PBC (Samsury and Zipser 1995).

The subsequent evolution of storm structure, witnessed in the satellite images and aircraft observations, suggests that an eyewall forms a few hours later within the encircling outer convection (around 0500 UTC 9 September), and later consolidates as the main eyewall once the storm has almost finished intensifying (around 0900 UTC 10 September). Section 5c will further investigate the dynamical processes associated with eyewall formation inside of the PBC.

\section{Model setup and sensitivity experiments}

The structure of Sinlaku at the beginning and during rapid intensification is interesting for addressing the sensitivity of intensity and track forecast to initial storm structure. This section presents the numerical tools used to initialize 72-h forecasts at 0000 UTC 9 September 2008 with various initial wind distributions.

\section{a. Numerical model}

Forecasts are run using the Australian Bureau of Meteorology's hydrostatic Tropical Cyclone Limited Area Prediction System (TC-LAPS; Davidson and Weber 2000). It utilizes high-order numerics and advanced physical parameterizations including a bulk explicit microphysics scheme and a mass flux convection parameterization. The TC-LAPS model was operational over the Australian region and northwest Pacific between 1999 and 2009 and was quite competitive by international standards: mean track and intensity errors at $48 \mathrm{~h}$ were $261 \mathrm{~km}$ and $22 \mathrm{hPa}$, respectively (Davidson et al. 2006).

Numerical experiments are carried out at $15-$ and $5-\mathrm{km}$ horizontal resolution using a triply nested relocatable mesh with 29 vertical levels and full physics. With $300 \times$ 300 grid points, the $15-\mathrm{km}$ resolution domain ranges from $0^{\circ}$ to $45^{\circ} \mathrm{N}$ and from $100^{\circ}$ to $145^{\circ} \mathrm{E}$. The $5-\mathrm{km}$ resolution grid stretches from $10^{\circ}$ to $30^{\circ} \mathrm{N}$ and from $120^{\circ}$ to $140^{\circ} \mathrm{E}(400 \times 400$ points $)$. The fine-mesh forecast is oneway nested in the coarse grid.

The storm center is diagnosed at the minimum surface pressure location in model outputs. Other methods such as 850 -hPa maximum cyclonic vorticity give consistent results and suggest that within the precision we are working, the radial structure is not significantly sensitive to the center location.

\section{b. Vortex specification}

The TC-LAPS model uses a unique and sophisticated vortex specification (Davidson and Weber 2000; Davidson et al. 1993). It includes the construction of a synthetic three-dimensional vortex from which "synthetic observations" can be extracted at different radii. That vortex is built using an analytical surface pressure profile (described in section 3c) together with information contained in operational advisories from TC warning centers (past and present location, central pressure, and storm size as defined by the ROCI). The current movement of the storm is added to create vortex asymmetries (e.g., Bender 1997).

A coarse-resolution analysis (and forecast) is first obtained by filtering out the misplaced TC circulation and assimilating synthetic vortex data in the large-scale analysis obtained from ACCESS-G (Puri et al. 2010). A subsequent initialization for fine-mesh prediction is conducted. Synthetic observations are extracted at smaller radial intervals and merged with conventional observations. They are assimilated at high-resolution into the coarse-resolution bogused analysis. The synthetic vortex does not explicitly include a secondary circulation and the associated ascent field, or a TC boundary layer where gradient wind balance cannot be assumed. Diabatic dynamical nudging allows the generation of such important features. The forecast model runs from $24 \mathrm{~h}$ prior to the base time of the forecast, and is nudged toward the 6-hourly objective analyses that include the synthetic vortex. At high resolution, only weak nudging is performed on the surface pressure and analyzed vorticity.

In short, the benefits of the diabatic, nudging initialization are that the initial condition will contain: an accurate representation of the environment, a vortex circulation consistent with the observed characteristics of the storm, a secondary circulation, boundary layer structure, and vertical motion field consistent with the primary circulation, and a vortex that is mostly in balance and consistent with the model's 
resolution, dynamics, and physics (Davidson and Weber 2000).

\section{c. Bogus}

The symmetric vortex is built using a revised version of the original Fujita (1952) surface pressure profile. Developed on an extended best-track dataset, it fits well vortex intensity and structure estimates: central pressure $\left(p_{c}\right)$, maximum wind (VMAX), RMW, R34, and ROCI. The pressure profile is given by Ma et al. (2012):

$$
P=1-\left[1+\varepsilon\left(\frac{r}{r_{\mathrm{cm}}}\right)^{\lambda}\right]^{-(1 / \varepsilon)},
$$

where $r_{\mathrm{cm}}$ is the radius of maximum cyclostrophic tangential wind, and $P(r)$ represents the normalized surface pressure profile following Schloemer (1954) to remove variations due to differing central and ambient pressures:

$$
P=\frac{p-p_{c}}{p_{\infty}-p_{c}}
$$

where $p$ is pressure at radius $r, p_{c}$ is the central pressure, and $P_{\infty}$ is the environmental pressure [represented by the pressure of the outermost closed isobar (POCI) plus a 1-hPa positive adjustment].

The coefficients $\varepsilon$ and $\lambda$ are derived from maximum cyclostrophic $\left(v_{\mathrm{cm}}\right)$ and gradient wind $\left[v_{g}(r)\right]$ at specific radii:

$$
\begin{gathered}
v_{\mathrm{cm}}=\sqrt{\frac{p_{\infty}-p_{c}}{\rho} \lambda(1+\varepsilon)^{-(1 / \varepsilon)-1}} \\
v_{g}(r)=-\frac{r f}{2} \\
+\sqrt{\frac{r^{2} f^{2}}{4}+\frac{p_{\infty}-p_{c}}{\rho} \lambda\left(\frac{r}{r_{\mathrm{cm}}}\right)^{\lambda}\left[1+\varepsilon\left(\frac{r}{r_{\mathrm{cm}}}\right)^{\lambda}\right]^{-(1 / \varepsilon)-1}}
\end{gathered}
$$

where $f$ is the Coriolis parameter, and $\rho$ is the air density. While $v_{\mathrm{cm}}$ and $r_{\mathrm{cm}}$ can be obtained directly from TC advisories (the difference with VMAX and RMW is of small order), $\varepsilon$ and $\lambda$ cannot be obtained analytically. In practice possible pairs of coefficients are tested (Ma et al. 2012) to fix winds at some specified outer radii, for example 34-kt winds at R34, and thus build the vortex outer structure from observationally based operational estimates.

Equations (3) and (4) indicate that this idealized profile $P(r)$ relies on three intensity parameters (VMAX, $p_{c}, \mathrm{POCI}$ ) and two size parameters (RMW, R34). While $p_{c}$ and ROCI are systematically estimated in operational advisories, other parameters can be absent or uncertain (RMW, R34). Therefore, an additional relation described by Weber (2006) is needed in the operational routine. From TC advisories, this model automatically calculates the key parameters VMAX, POCI, RMW, and R34 that are needed to construct the synthetic vortex. From $p_{c}$ and ROCI, as well as the storm center latitude, the model retains the POCI from the largescale objective analysis. A consistent set of storm parameters (VMAX, $p_{c}$, POCI, RMW, R34) is then computed by integration of the $f$-plane gradient wind equation for an inertially stable, axisymmetric, tangential wind profile. To sum up, this vortex specification scheme allows direct evaluation of the forecast sensitivity to RMW and R34 because the vortex-size parameters can be easily adjusted independently of each other and independently of $p_{c}$ and ROCI.

\section{d. Set of experiments}

Sinlaku is still weak (45 kt, $990 \mathrm{hPa})$ at 0000 UTC 9 September, right after the onset of RI, and the storm structure is not clearly defined (section 2c). There is considerable uncertainty in storm size estimates and the real-time values for RMW and ROCI differ substantially between warning centers. Is the forecast influenced by such uncertainty?

Original estimates for the ROCI are $185 \mathrm{~km}$ (Darwin Tropical Cyclone Warning Centre) and $370 \mathrm{~km}$ (Joint Typhoon Warning Center). The ROCI can be difficult to estimate in real time as it is not a well-defined quantity and aircraft reconnaissance was not available for outer regions. Therefore, the ROCI is revised to $400 \mathrm{~km}$ based on ACCESS-G analyses. This value provided a more reasonable representation of Sinlaku's observed intensification in early $15-\mathrm{km}$ resolution simulations (not illustrated).

The large-scale flow is reasonably well depicted by the model (not illustrated), which suggests that improvements in track prediction are likely to be found in vortex structure initialization rather than in improved depiction of the large-scale environment in this case. The $15-\mathrm{km}$ resolution forecast is insensitive to the kind of boundary conditions (interpolated ACCESS-G analyses or coarse-resolution forecast).

A hierarchy of 72-h forecasts, initialized with a broad range of RMW and R34 values, is consequently run at 15-km resolution (Table 1, simulations SM6 to SM18). Parameters are scaled around the mean numbers obtained from Weber's statistical model (Weber 2006) using a $400-\mathrm{km}$ ROCI and estimates of $p_{c}$ issued by the Darwin TC Centre. Initial RMW values (Table 1) may be compared to operational estimates (55 and $46 \mathrm{~km}$ for 
TABLE 1. Set of 72-h forecasts carried out on Typhoon Sinlaku from base time 0000 UTC 9 Sep 2008. Indicated for each numerical experiment are the model resolution, boundary conditions, and vortex-size parameters $(\mathrm{km})$ averaged over a 12 -h period prior to the base time of the forecast. Parameters ROCI, R34, and RMW are the radii of outer closed isobar, 34-kt wind speed, and maximum wind speed, respectively.

\begin{tabular}{lcccrr}
\hline \hline Expt & Resolution & $\begin{array}{c}\text { Boundary } \\
\text { conditions }\end{array}$ & ROCI & R34 & RMW \\
\hline SM6 & $0.15^{\circ}$ & ACCESS-G analyses & 400 & 165 & 45 \\
SM7 & $0.15^{\circ}$ & ACCESS-G analyses & 400 & 165 & 75 \\
SM8 & $0.15^{\circ}$ & ACCESS-G analyses & 400 & 165 & 100 \\
SM9 & $0.15^{\circ}$ & ACCESS-G analyses & 400 & 220 & 45 \\
SM10 & $0.15^{\circ}$ & ACCESS-G analyses & 400 & 220 & 75 \\
SM11 & $0.15^{\circ}$ & ACCESS-G analyses & 400 & 220 & 100 \\
SM12 & $0.15^{\circ}$ & ACCESS-G analyses & 400 & 280 & 45 \\
SM13 & $0.15^{\circ}$ & ACCESS-G analyses & 400 & 280 & 75 \\
SM14 & $0.15^{\circ}$ & ACCESS-G analyses & 400 & 280 & 100 \\
SM15 & $0.15^{\circ}$ & ACCESS-G analyses & 400 & 335 & 55 \\
SM16 & $0.15^{\circ}$ & ACCESS-G analyses & 400 & 335 & 110 \\
SM17 & $0.15^{\circ}$ & ACCESS-G analyses & 400 & 335 & 165 \\
SM18 & $0.15^{\circ}$ & ACCESS-G analyses & 400 & 335 & 220 \\
SS15 & $0.05^{\circ}$ & $0.15^{\circ}$ forecast & 400 & 335 & 55 \\
SS18 & $0.05^{\circ}$ & $0.15^{\circ}$ forecast & 400 & 335 & 220 \\
\hline
\end{tabular}

the Darwin and Joint Typhoon Warning Centers, respectively). The three intensity parameters (VMAX, $p_{c}$, and POCI) are untouched and preserved in all simulations. The rationale for testing a broad range of vortex scales is that the motion is not sensitive to details of the inner core, but may be influenced by vortex structure at larger radii (Carr and Elsberry 1997), including the location of the radius of maximum wind. The use of rather large RMW values can be justified from the satellite cloud imagery, which indicates multiple convective bands, with possibly associated multiple wind maxima (section 2c).

Forecasts at $5-\mathrm{km}$ resolution are further used to simulate the role of the PBC (Figs. 4a,b) in the future evolution of storm structure and intensity. Vortices initialized with either RMW $=200 \mathrm{~km}$ (SS18), corresponding to the observed encircling outer convective band, or RMW $=55 \mathrm{~km}$ (SS15), corresponding to the eyewall that develops and consolidates within the PBC, are compared. These forecasts are nested in the corresponding 15-km resolution simulations SM15 and SM18, and run using the same bulk explicit microphysics and convective parameterization (Table 1).

Diagnoses consist of verifying track and intensity forecasts and how their accuracies change with evolving vortex-size parameters. Relevant questions are as follows: Does TC-LAPS reproduce the RI period? Has the initial vortex structure any role to play in the track (section 4), intensity, and structure forecasts (section 5)? If so, what are the critical vortex parameters and the corresponding dynamical mechanisms?

\section{Impact of vortex initialization on the track forecast}

\section{a. Track forecast}

Large RMW initializations consistently improve the track forecast beyond 1200 UTC 10 September, due to a better representation of the motion change from east to north during the $\beta$-effect period (Figs. 5 and 6 , left panels). A scatterplot of 72-h track errors versus initial RMW (Fig. 7) highlights this trend, which stays true for smaller R34 values (experiments SM6 to SM11). The 72-h error between SM15 and SM18 is reduced by $40 \%$. The rather small degradation found at short lead times stands within the noise of any numerical prediction system (it averages out to $7 \mathrm{~km}$ over the whole 0-36-h period for SM6 to SM18 simulations).

Note that all other numerical weather prediction guidance based on 0000 UTC 9 September also showed a forecast track to the right of the observed track beyond $36 \mathrm{~h}$, indicating that the error pattern was not an artifact of TC-LAPS, but rather that there was a systematic error in track forecasts, which may have been associated with incorrect vortex structure (defined by vortex size) or incorrect steering flow. By perturbing the monsoon trough or weakening the midlatitude trough north of Sinlaku, Komaromi et al. (2011) obtained large reduction of the 120-h forecast track error from base time 0000 UTC 10 September. Improvement was suggested to result from a combination of the weaker southeasterly flow in the Pacific ridge and the beta drift of Sinlaku. The very small changes in TC-LAPS track forecasts at short lead times, compared with the occasional large degradation in Komaromi et al. (2011) at 48 h, suggests that overall improvements of Sinlaku's track forecast after 0000 UTC 11 September were likely a combination of both factors (environmental influences and vortex structure).

Figure 8a shows vortex motion for SM15 and SM18 after 30 (left panels) and $48 \mathrm{~h}$ (right panels). Storm motion (Vs) is calculated over a 12 -h period centered on the analysis time; environmental steering $(\mathrm{Ve})$ is estimated by the averaged flow over a $200-800-\mathrm{km}$ annulus in the 850-250-hPa layer; departure from that steering at $48 \mathrm{~h}(\mathrm{Vd}=\mathrm{Vs}-\mathrm{Ve})$ includes possible $\beta$ propagation or convective asymmetries. The estimation of Ve excludes the vortex symmetric circulation from the environmental wind field, but is somewhat contaminated by the inclusion of a significant portion of the meridional flow between the hypothetical gyres. Conversely, the westward twist of the gyres mostly occurs over the inner-core region of the storm, so that $\mathrm{Vd}$ would mostly reflect a westward $\beta$ drift plus a small part of the poleward drift. 
$(\mathrm{SM} 12)$

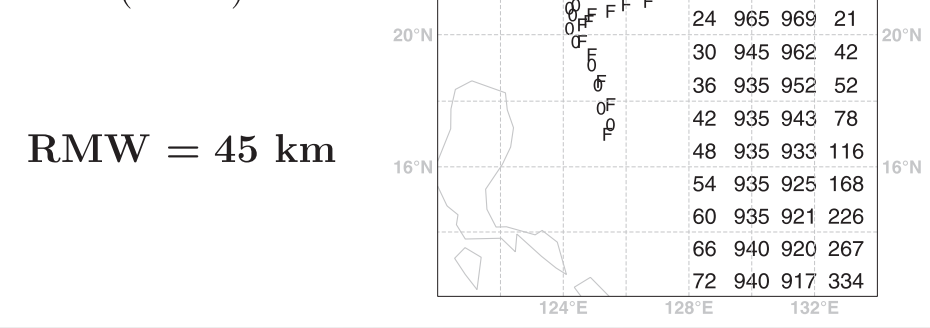

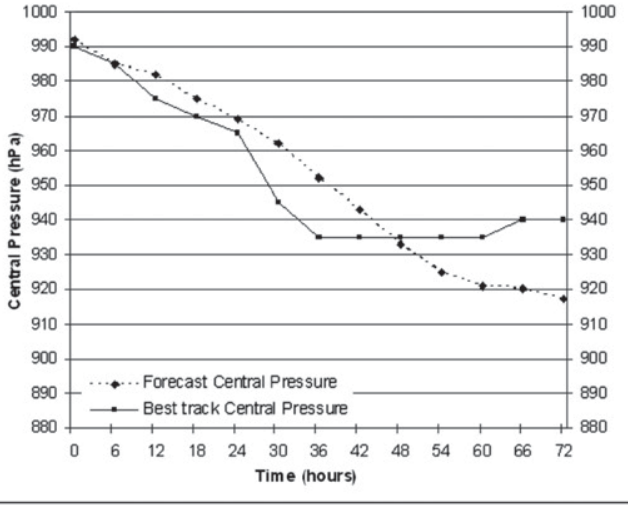

(SM13)

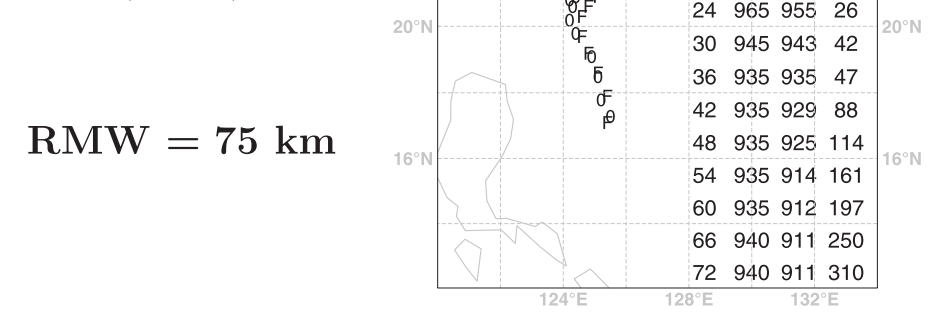

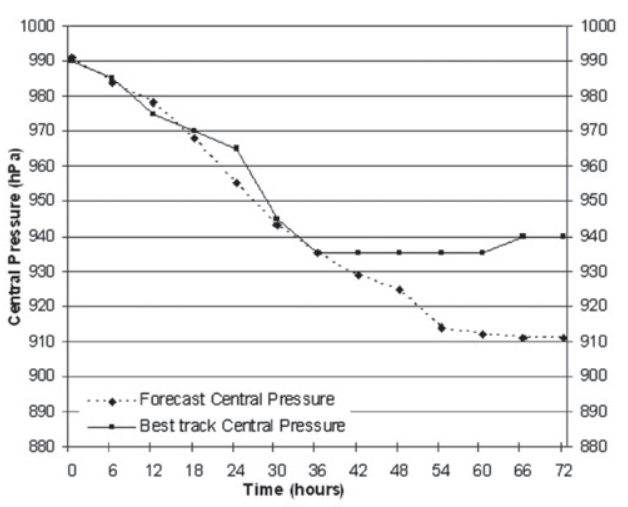

(SM14)

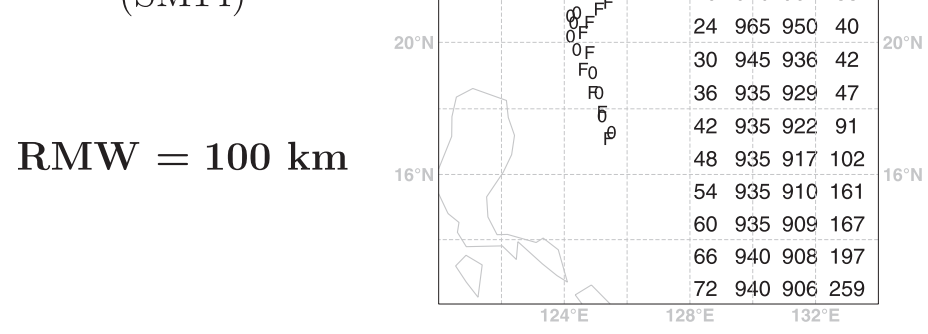

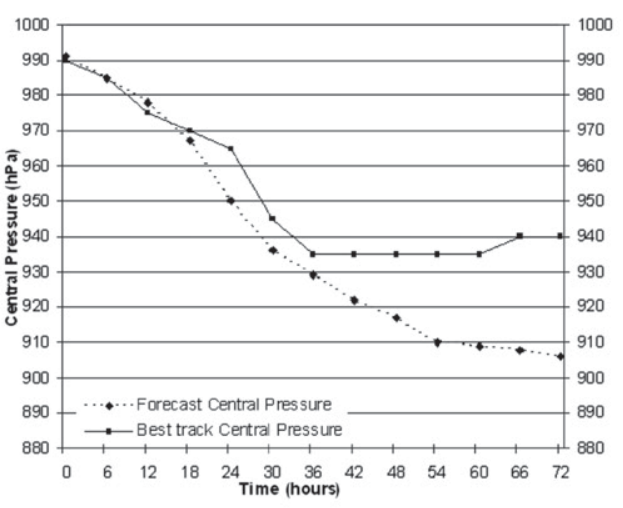

FIG. 5. Typhoon Sinlaku (left) observed (O) and predicted (F) track and (right) central pressures from base time 0000 UTC 9 Sep 2008. (from top to bottom) The $0.15^{\circ}$ resolution 72-h forecasts (SM12, SM13, and SM14) initialized with R34 = $280 \mathrm{~km}$ and different RMW values as indicated. Column values in track panels (at left) display estimated (OBS) and forecast (FORC) central pressures (hPa), as well as track errors (TERR, km) at 6-h intervals. Best-track data are obtained from IBTrACS.

The predicted steering flow Ve is weak and constant (about $2.5 \mathrm{~m} \mathrm{~s}^{-1}$ ). It shifts from north-northeastward to northeastward (east northeastward) in SM18 (SM15), suggesting that initial vortex size (and structure) controls the way the storm interacts with its environment and gradually deforms it (starting from the same basic flow and vortex location at $30 \mathrm{~h}$ ). Of course, there is a feedback from the environment afterward: once the vortex follows another path, it evolves in a slightly altered steering flow that can contribute further to its differing track. Storm motion shifts, too, but Vd becomes significant at $48 \mathrm{~h}$, especially for the large initial 


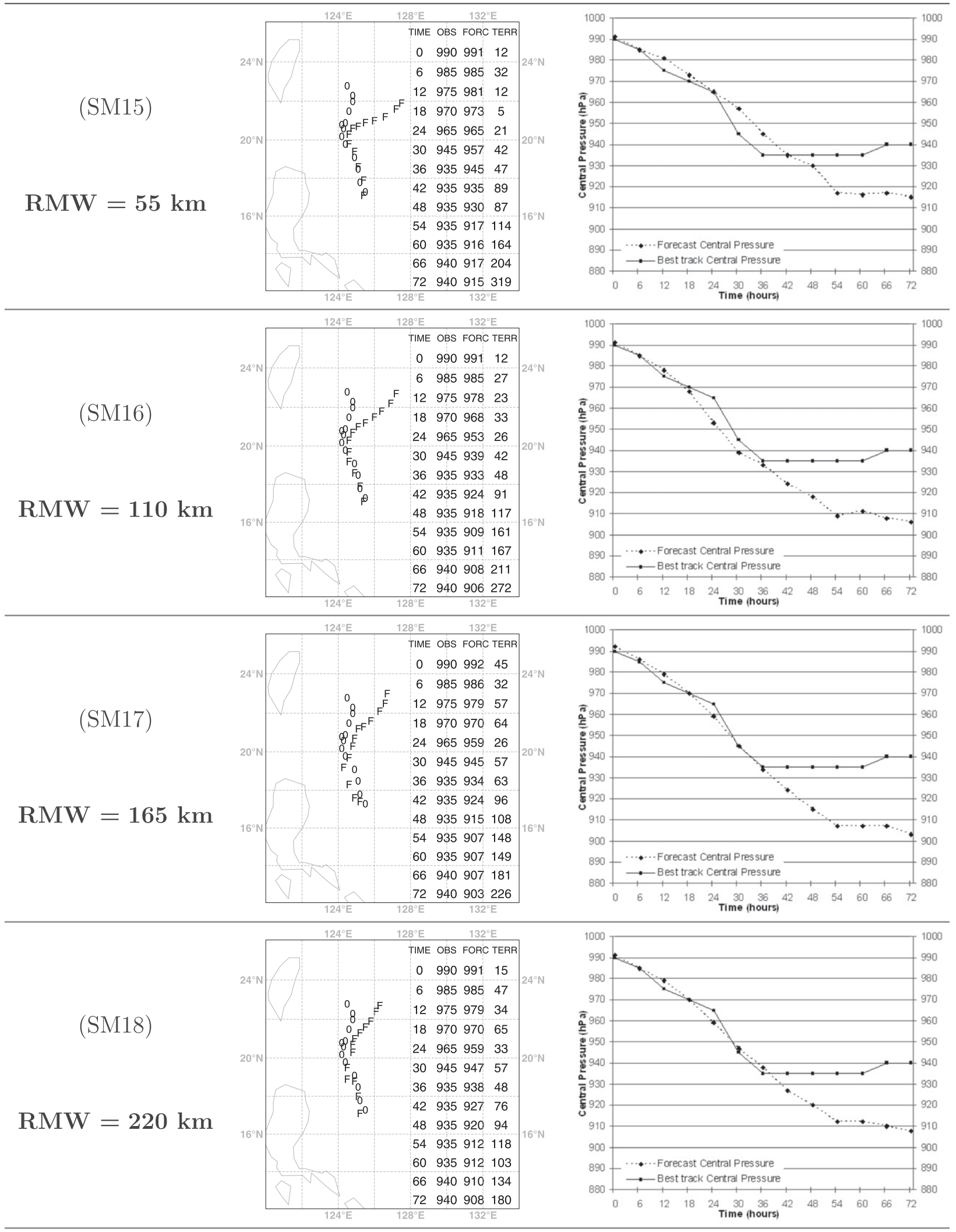

FIG. 6. As in Fig. 5, but for simulations SM15, SM16, SM17, and SM18 (R34 = $335 \mathrm{~km}$ and different RMW values as indicated in the legend). 


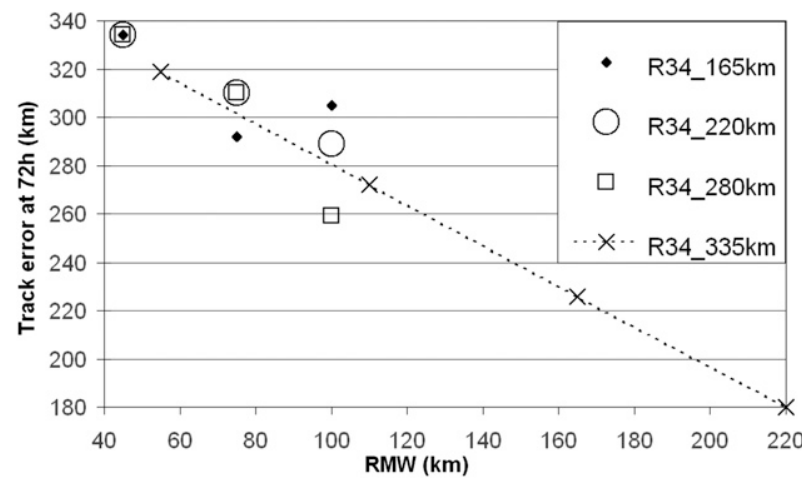

FIG. 7. The 72-h forecast track error (km) vs initial RMW (km) for $0.15^{\circ}$ resolution experiments SM6-SM18 (Table 1). Experiments are classified by groups of initial R34 values as indicated in the legend.

vortex $\left(1 \mathrm{~m} \mathrm{~s}^{-1}\right)$. The apparent west-northwest departure from the environmental flow and the poleward movement of the storm suggests that TC-beta interaction must be accounting for the motion change.

Computation of the wavenumber- 1 asymmetry (similar to section 2) on the difference in streamfunction between SM18 and SM15 provides compelling support for the generation of stronger $\beta$ gyres in the large SM18 vortex (Fig. 8b). By canceling the environmental steering until $48 \mathrm{~h}$ (when the predicted centers are not separated by more than $0.4^{\circ}$ ), this method allows extraction of the finite amplitude effect a large storm can have in modifying the surrounding flow and altering the steering. The counter-rotating circulations have the same orientation, location, and strength as the gyres found in ACCESS-G analyses (Fig. 3, right panels, same contour intervals), although they are more clearly defined here. The flow within $100 \mathrm{~km}$ of the selected center is not uniform (especially at $48 \mathrm{~h}$ ) and shall not be taken into account for dynamical analysis of vortex motion. It indeed depends on the definition of the coordinate system origin (SM18 center here) used to extract the symmetric component in the Fourier analysis [this is similar to the computation of inner gyres in Fiorino and Elsberry (1989)].

\section{b. Importance of initial storm structure on $\beta$ propagation}

Analyses (section $2 \mathrm{~b}$ ) and simulations both support the importance of $\beta$ effect in defining track changes following RI. As the storm slows down, $\beta$ propagation becomes gradually significant under weak environmental influences. Experiments with TC-LAPS illustrate that the northwestward deviation induced by the $\beta$ effect depends on the specification of the initial vortex size. It acts more efficiently when the initial wind distribution is specified with sufficient strength and extent especially at outer radii (larger initial RMW), consistent with Chan and Williams (1987). The importance of $\beta$ propagation for this case may explain why the radius of gale-force wind does not have a significant impact on the track forecast (see 72-h errors, Fig. 7). At the R34, vorticity gradients and storm winds are weaker than at the RMW and must produce a smaller $\beta$-propagation contribution. Such lack of sensitivity to the R34 differs from Cao et al. (2011) and suggests a possible case dependency for storms with strong outer wind structures in weak environmental flows. The final forward speed of their artificial vortices increased with smaller wind profile decay factors (i.e., with stronger winds supplied at outer radii) for RMW ranging from 30 to $110 \mathrm{~km}$ in $36-\mathrm{km}$ resolution forecasts.

\section{Prediction of rapid intensification and vortex structure evolution}

\section{a. Impact of vortex initialization on the intensity forecast}

Experiments SM6 to SM16 indicate that the intensification rate grows in phase with increasing initial RMW values (e.g., Fig. 5), regardless of the prescribed R34 value, which has no significant impact on the intensity forecast. This is highlighted with a scatterplot of 72-h predicted central pressure versus initial RMW (Fig. 9) where SM18, the rightmost point, appears as an outlier to the trend. The results obtained here for a real TC case differ from the semi-idealized simulations of Cao et al. (2011). The intensification rate was roughly similar among the suite of different initial RMW vortices, while final intensities were greater for less rapidly decaying initial wind profiles. A possible explanation for the intensification trend observed in TC-LAPS is that increasing the RMW while keeping the maximum wind constant increases the angular momentum at the RMW (and the total amount of vorticity available to be converged), giving the storm more potential to develop an intense inner core. This result follows from the circulation theorem, which states that the total vorticity within a region equals the circulation around that region. Taking the region $A$ to be that bounded by the maximum wind belt,

$\iint_{A} \zeta d A=\int_{0}^{2 \pi} v_{\max }(\theta) r_{\max }(\theta) d \theta \approx 2 \pi \overline{r_{\max }} \overline{v_{\max }}$

Hence if $v_{\max }$ remains constant, increasing the RMW will increase the integral of vorticity across the eye, even though it will also tend to decrease the peak value. Note 
(a)

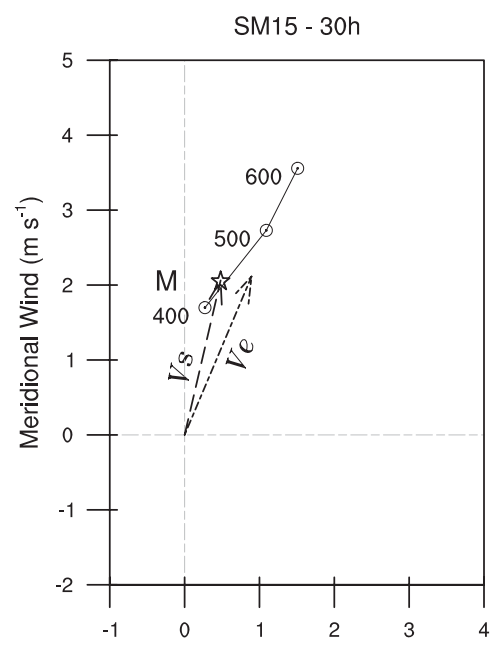

SM18-30h

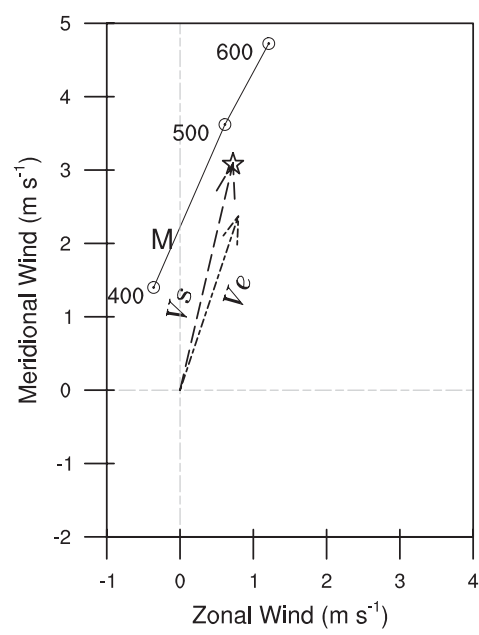

\section{(a)}
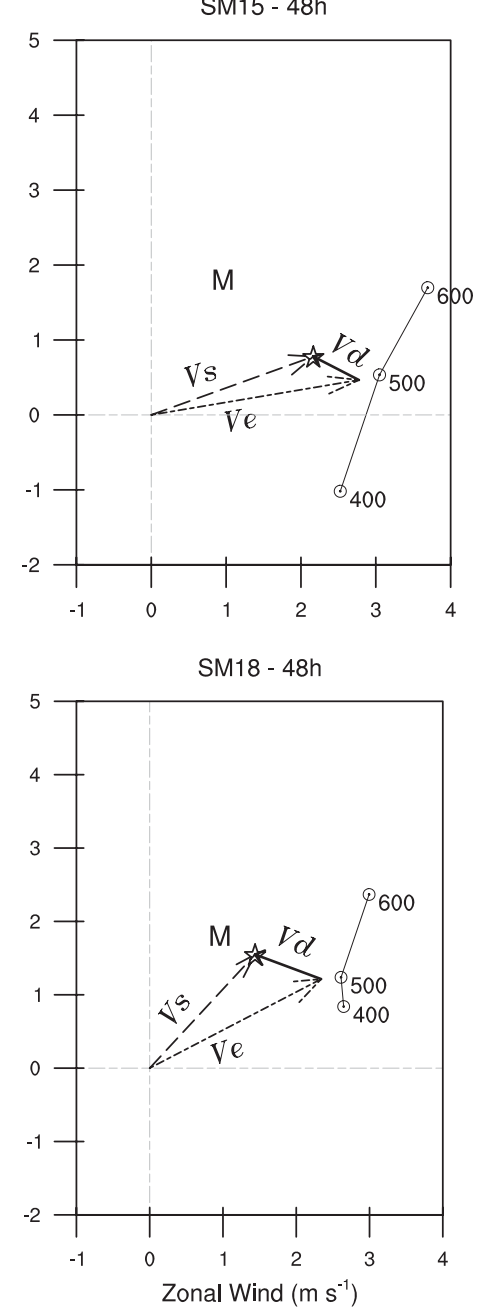

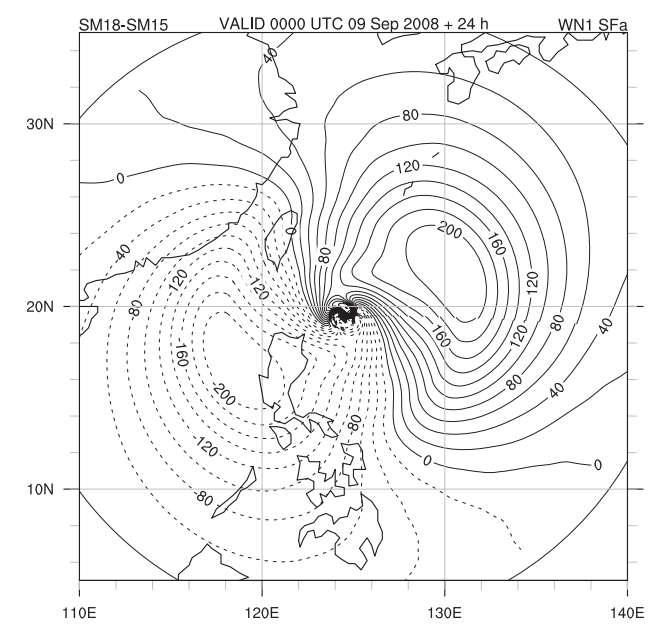

(b)

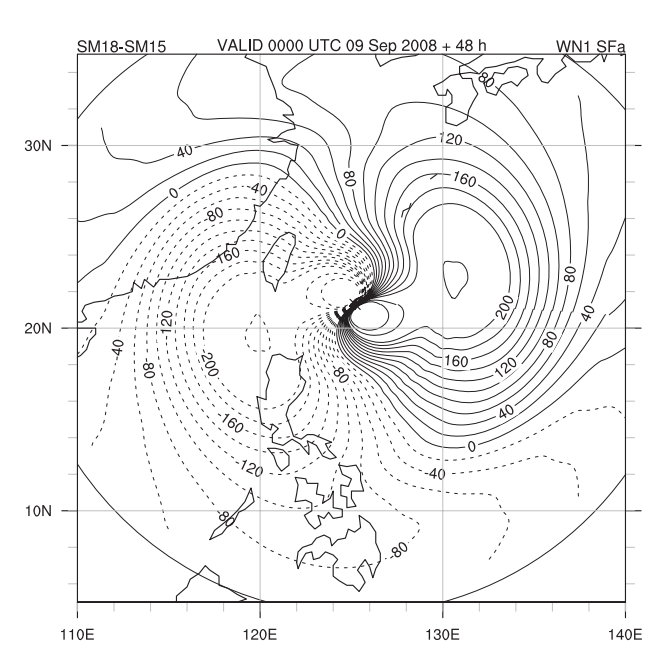

FIG. 8. (a) Hodographs at (left) 30 and (right) $48 \mathrm{~h}$ into the (top) SM15 and (bottom) SM18 simulations. Winds are averaged over a 200$800-\mathrm{km}$ annulus centered on the storm at 600,500 , and $400 \mathrm{hPa}$. Labels $\mathrm{M}$ and star ( $h$ ) indicate the storm speed obtained from the besttrack data and the forecast, respectively. Vectors represent the predicted mean environmental flow from 850 to $250 \mathrm{hPa}(\mathrm{Ve})$, storm motion vector $(\mathrm{Vs})$, and their difference at $48 \mathrm{~h}(\mathrm{Vd}=\mathrm{Vs}-\mathrm{Ve})$ that includes $\beta$ propagation. (b) As in Fig. 3 (right panels), but the wavenumber-1 asymmetry is calculated on the streamfunction field difference SM18 - SM15, at (top) 24 and (bottom) $48 \mathrm{~h}$ into the simulations. Computation of the asymmetry is performed around the predicted center of SM18.

that this result does not depend on the precise structure of the flow within $A$. Figures 6 and 9 show that once RMW exceeds $110 \mathrm{~km}$, this intensification trend fades (SM17) then reverse (SM18). The reasons for this are not fully understood at this time, but could possibly involve the fact that SM17 and SM18 have very large initial eye areas $A$ that could affect the inner-core vortex dynamics predicted by the model (e.g., formation of an inner eyewall, see section 5b). This might negate the application of the above theorem when vortex rearrangements are involved.

The previous $15-\mathrm{km}$ resolution experiments have demonstrated that an enhanced specification of the wind profile for Sinlaku can greatly improve TC-LAPS forecast. It evokes the need to better match each TC initial observed structure, which in turn relies on a greater understanding of storm structure evolution during RI, an aspect the following paragraphs examine.

\section{b. Evolution of the predicted vortex structure for SS15 and SS18}

We wish to understand the role of the PBC present near the onset of RI in storm evolution. Experiments are run at $5-\mathrm{km}$ resolution (Table 1) with initial RMWs of $55 \mathrm{~km}$ (SS15) and $220 \mathrm{~km}$ (SS18) following the observed cloud signatures (Figs. 4a and 4b). The high-resolution 


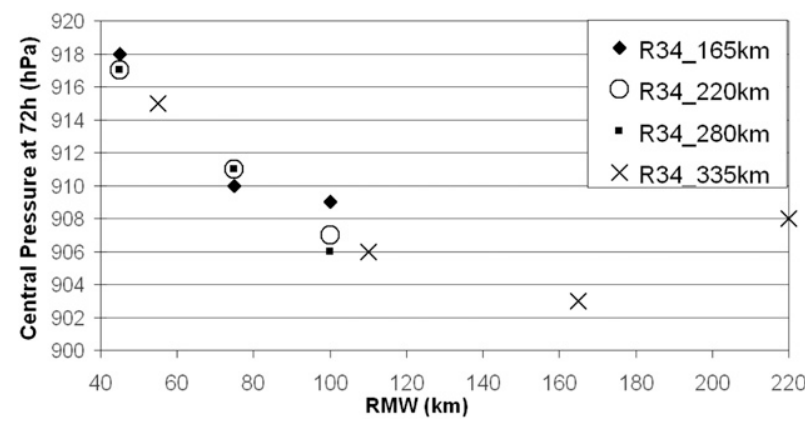

FIG. 9. As in Fig. 7, but for the 72-h central pressure forecast (hPa).

vortices keep a very similar track to their $15-\mathrm{km}$ resolution counterparts, yet an $11 \%$ reduction of track error is found at $72 \mathrm{~h}$ (Fig. 6 vs Fig. 10). Nevertheless, their final intensities diverge. The small vortex (SS15) overintensifies to below $900 \mathrm{hPa}$, consistent with the results of Persing and Montgomery (2003), Hausman et al. (2006), or Van Sang et al. (2008) who documented the tendency of models to form more intense storms with increasing spatial resolution. Simulation SS18, however, has a different response that persists when we vary physical parameterizations (not shown). The two vortices SS15 and SS18 track over a similar oceanic environment (Fig. 11) that could not cause the significant predicted intensity difference. Instead, it is suspected that inner-core processes, some of which can be predicted at $5-\mathrm{km}$ resolution, might define the pathway to rapid intensification.

Figure 12 presents the structure evolution of the two vortices throughout the 72-h forecast: values of central pressure (Pc), VMAX, RMW, R34, and maximum vertical relative vorticity (RV_max), are calculated every hour at the $0.975 \sigma$ level ( $\sigma=$ pressure/surface pressure) out to a radius of $500 \mathrm{~km}$. This level is close to the altitude where the actual storm parameters are measured or estimated. For validation, crosses indicate every $6 \mathrm{~h}$ the corresponding R34 values computed from Weber (2006) statistical model using both ROCI values (from ACCESS-G analyses) and best-track estimates of central pressure, asterisks denote estimates for the actual typhoon obtained from IBTrACS (Knapp et al. 2010), and circles mark RMW aircraft measurements. Figure 12 shows that vortex-size parameters have already evolved from their specified values (Table 1) at the base time of the forecast. The initialization phase has indeed allowed the vortex to adjust to the model characteristics, while the synthetic data and standard observations were objectively analyzed. Nevertheless, the characteristics of the two vortices stay markedly distinct at the base time of the forecast (as prescribed).
The observed increase in R34 during the 72-h period and contraction of the RMW during the first $12 \mathrm{~h}$ is predicted in both simulations. However, though SS15 is the vortex that initially best fits the estimated vortexsize parameters R34 and RMW, SS18 produces improved verification for both track and intensity metrics that are moderately reliable for stronger storms. Although it is possible that the reasons that SS18 produces the most accurate forecast are not entirely correct, it is nevertheless reasonable to hypothesize that the initial storm structure in SS18, for which we specified a RMW inferred from convective band location, is a better representation than SS15. This could suggest that, in this case, initial outer wind distribution may play a crucial role in progression of storm structure and intensity.

Further investigation reveals that the primary and secondary circulations of SS15 and SS18 are very different. The radial profiles of azimuthally averaged tangential (Vt) and radial (Vr) velocities in the boundary layer (Fig. 13) show a secondary wind maximum developing within the inner core of the large storm (SS18) between 12 and $30 \mathrm{~h}$. It seems that the SS18 forecast forms a double eyewall which eventually merge at a slightly larger RMW than SS15. One main eyewall consolidates about $90 \mathrm{~km}$ away from the TC center, contracting farther to about $70 \mathrm{~km}$ by the end of SS18 forecast.

\section{c. The interior eyewall formation}

The structure evolution in SS18 seems consistent with the patterns depicted in the satellite images (section 2c) at the beginning of RI. The model managed to reproduce the eyewall that was forming inside the $\mathrm{PBC}$, which was simulated using RMW $=220 \mathrm{~km}$. This event that we simply call the interior eyewall formation (IEF) is independent of the secondary eyewall formation observed later in Typhoon Sinlaku and discussed in $\mathrm{Wu}$ et al. (2012) and Huang et al. (2012). The investigation here rather corresponds to the development of the main eyewall in a weak storm that begins to organize and intensify.

To obtain a deeper understanding of the dynamics of eyewall formation inside an imposed large RMW, we examine the evolution of the surface pressure, vertical motion, and mixing ratio at $700 \mathrm{hPa}$ (Fig. 14, from left to right). Prior to IEF (top panels), the circulation is characterized by a radius of maximum pressure gradient (and RMW) located at about $160 \mathrm{~km}$, with a generally featureless weak-gradient structure at smaller radii (Fig. 14a). At this time, ascent is restricted to an annulus just inside of the radius of maximum pressure gradient (Fig. 14b). Virtually no ascent is occurring inside a 

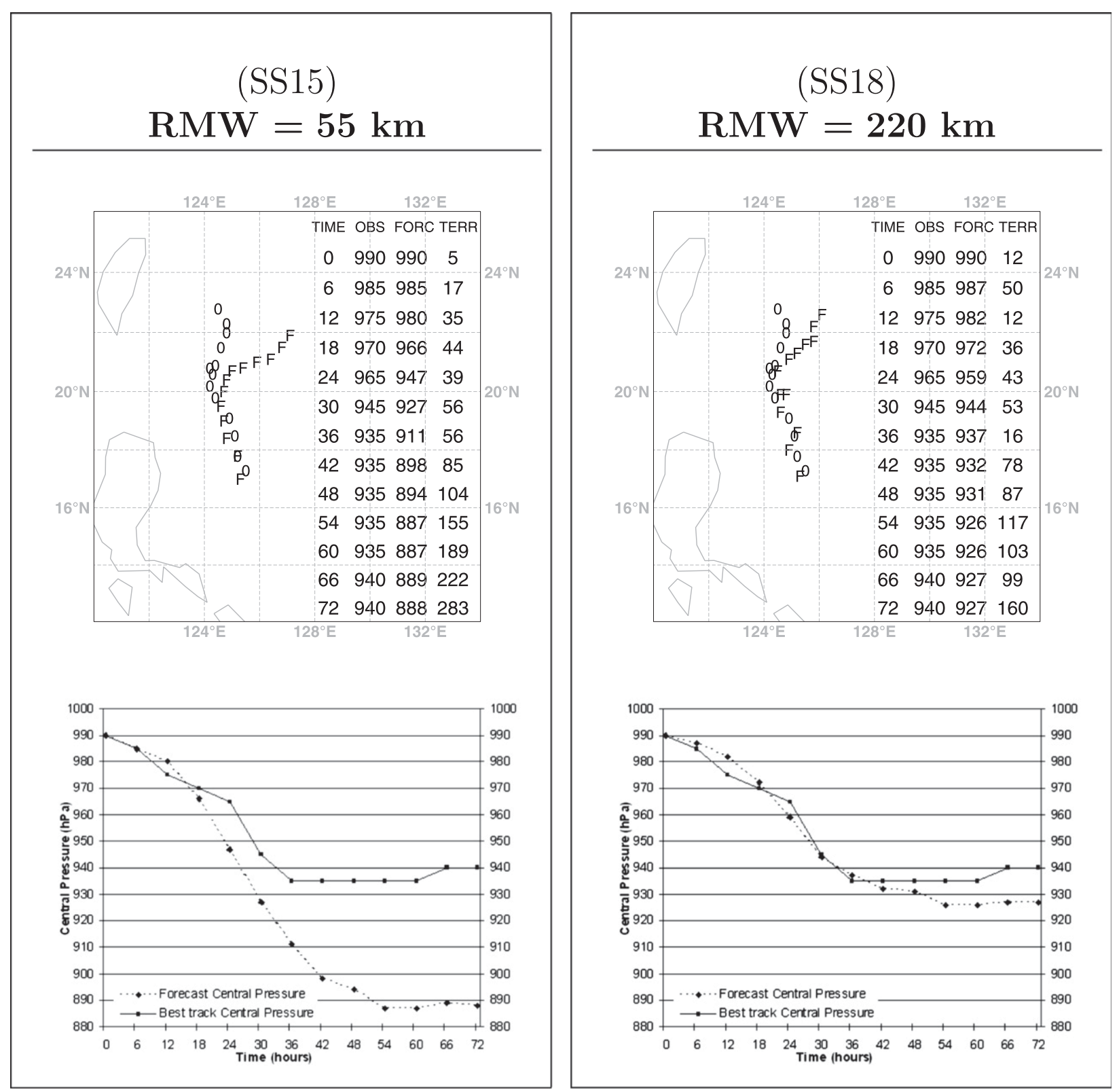

FIG. 10. As in Fig. 5, but for $0.05^{\circ}$ resolution forecasts SS15 and SS18 (R34 = $335 \mathrm{~km}$ and different RMW values as indicated in the legend).

well-defined primary eyewall. During IEF (middle panels), a number of updraft cells or VHTs (Montgomery et al. 2006) can be seen inside of the primary eyewall (Fig. 14e). They produce locally enhanced pressure gradients (Fig. 14d), and low-level winds (not shown), at radii inside of the system-scale radius of maximum pressure gradient (Fig. 14d). That is, the ascent field suggests a second annulus of upward motion inside the first ring, consistent with the radial profiles shown in Fig. 13 (and Fig. 15 later). These features are highlighted with circles (Fig. 14e). Moistening has not only continued at the radius of maximum pressure gradient, but also at smaller radii (Fig. 14f). After IEF (bottom panels), the radius of maximum pressure gradient (and RMW) has contracted to approximately $90 \mathrm{~km}$ (Fig. 14g). The center of the circulation is uniquely defined with upward motion concentrated within a main eyewall region (Fig. 14h). The generation of VHTs, as well as the merging and axisymmetrization of neighboring vorticity anomalies (Van Sang et al. 2008), are possible mechanisms based on model simulations that could be leading to the formation of the eyewall.

Radial profiles of the $0.975 \sigma$-level vertical motion omega averaged along azimuthal circles (Fig. 15) also 


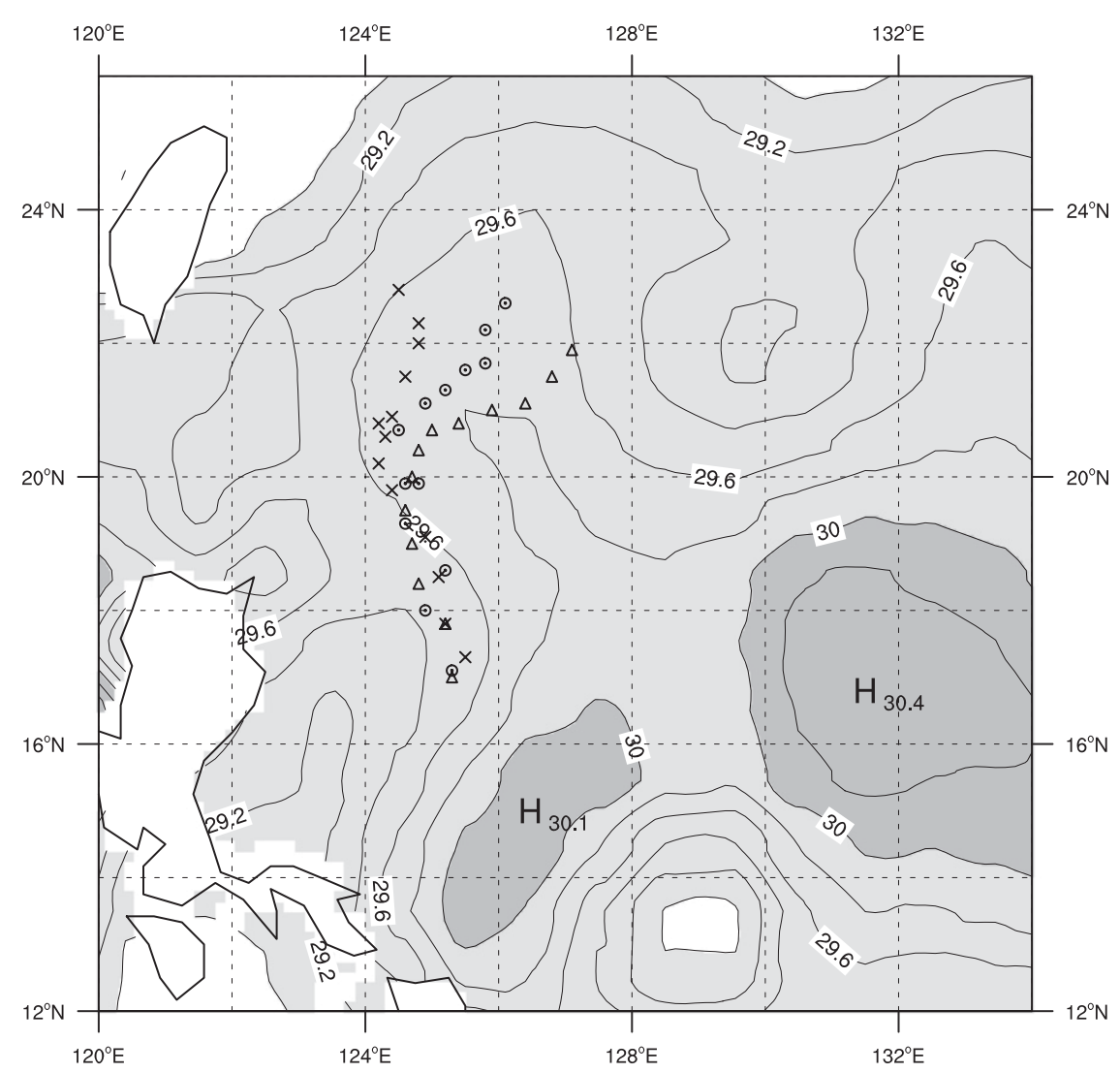

FIG. 11. Sea surface temperature field in TC-LAPS obtained from a weekly collection of satellite and ships observations during the period $1-7 \mathrm{Sep} 2008$. Contour interval is $0.2^{\circ} \mathrm{C}$; light (dark) shading indicates values between $29^{\circ}$ and $30^{\circ} \mathrm{C}\left(>30^{\circ} \mathrm{C}\right)$. The location of the storm center at 6-h intervals from 0000 UTC 9 Sep to 0000 UTC 12 Sep 2008 is indicated by a marker [crisscross $(\times)$ for IBTrACS data, triangle $(\triangle)$ for SS15, and an encircled dot $(\odot)$ for SS18].

suggest strong regions of ascent developing in the low boundary layer at inner radii within $80 \mathrm{~km}$ from the TC center (inner rectangle in Fig. 15b). The secondary tangential wind speed maximum develops within that region of convective instability. The region between the two tangential wind speed maxima is instead characterized by weaker mean ascent from the boundary layer (Fig. 15b, in between the two rectangles, and Fig. $15 \mathrm{c}$ ) and less mean radial inflow (bottom-right panel of Fig. 13).

\section{d. Discussion on the predicted structure: Two phases of the vortex}

Examination of the radial profiles of mean vertical relative vorticity (not illustrated) shows that the SS18 vortex undergoes different phases, switching from a vorticity ring to a stable monopolar distribution, and back to a ring, similar to the patterns observed for Hurricane Katrina (Nguyen et al. 2011), although the timing and number of cycles are different. Such phases may explain (i) the rapid development of VHTs in the region of positive relative vorticity gradient of the ring structure, and (ii) the way the mean flow rapidly strengthens between 24 and $36 \mathrm{~h}$ (Fig. 13) during transition from the monopole to the final ring structure (Nguyen et al. 2011). Vortical hot towers could explain, through stretching arguments, the sudden increase in the maximum of relative vorticity (RV_max) observed between 12 and $20 \mathrm{~h}$ (Fig. 12). Also, the downdraft regions that surround the VHTs can suppress convection at outer radii and account for the region of weaker mean ascent previously identified between the two tangential wind speed maxima (Fig. 15). This justifies why neither omega nor $\mathrm{Vt}$ grow much within the primary outer eyewall before $24 \mathrm{~h}$.

Additional diagnoses are needed to examine vortex transitions and investigate the role of vortex Rossby waves: axisymmetrization of the vorticity produced by the VHTs from the inner core to the region of maximum winds (Montgomery and Kallenbach 1997) could explain the outward spreading of the inner secondary wind maximum observed in our simulation. 


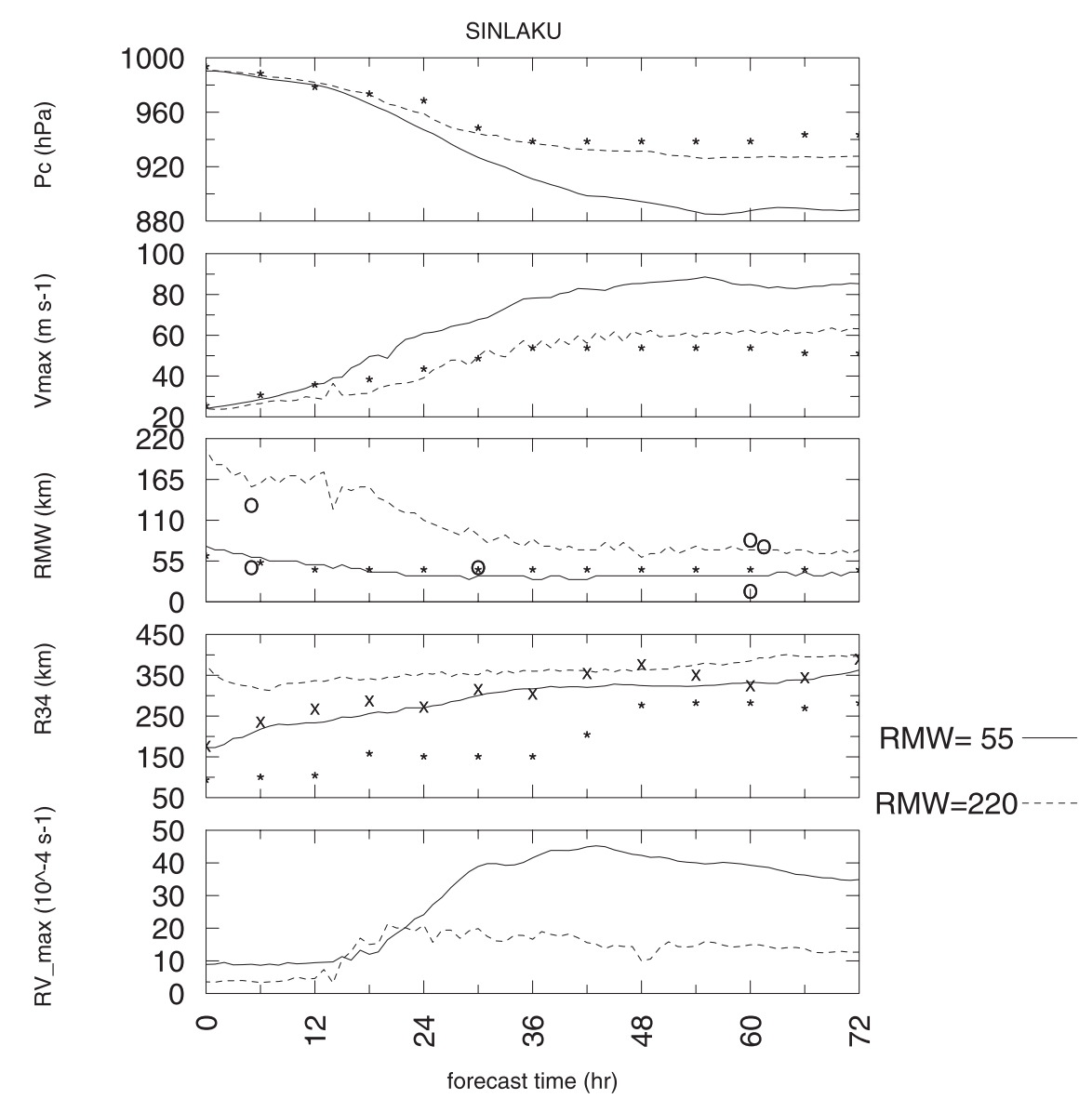

FIG. 12. (from top to next to last panel) Time series of storm parameters for experiments SS15 (RMW $=55 \mathrm{~km}$, solid line) and SS18 (RMW $=220 \mathrm{~km}$, dashed line). The stars $(*)$ denote estimated values of $p_{c}$ and VMAX (best-track data from the Tokyo Typhoon Center), of RMW (real-time estimates from Darwin Tropical Cyclone Warning Centre), and of R34 (best-track data from the Joint Typhoon Warning Center, sole provider) for Typhoon Sinlaku. The open circles $(\circ)$ show RMW estimates from aircraft missions. The crisscrosses $(\times)$ indicate R34 values calculated from Weber's statistical model. (bottom) Predicted values of maximum vertical relative vorticity (RV_max, $\left.10^{-4} \mathrm{~s}^{-1}\right)$.

\section{e. General discussion}

We believe the process we have diagnosed as IEF occurred in both the simulation and actual storm. This pattern has thus far not been observed in nature, at least with the current observing tools at our disposal. In particular, the observations and simulation suggest that the inward contraction of the eyewall may not always be a continuous process. The eyewall may instead contract inward in quantum jumps, such as suggested by the evolution of Vt for SS18 (Fig. 13), particularly when the RMW is large and the storm is undergoing RI. This process was not observed in the SS15 simulation, which was initialized with a unique ring of convection. That simulation did not form outer bands (not shown) and also did not yield the correct intensification.
In the light of the results obtained, it seems crucial to develop bogus schemes that allow for the specification of two regions of convection or two regions of maximum winds. Of course, a major issue is the estimation of multiple RMWs by operational centers with the common available observation techniques (as pointed out for Sinlaku). "Double (or multi) wind max bogus" schemes would allow a better representation and simulation of the structural organization of weak TCs when microwave imagery indicates a symmetric outer band of precipitation. They would also properly initialize the wind distribution within multiple convective bands for stronger TCs undergoing an eyewall replacement cycle. In general, these new schemes should contribute to improve TC forecasts (structure and intensity). 

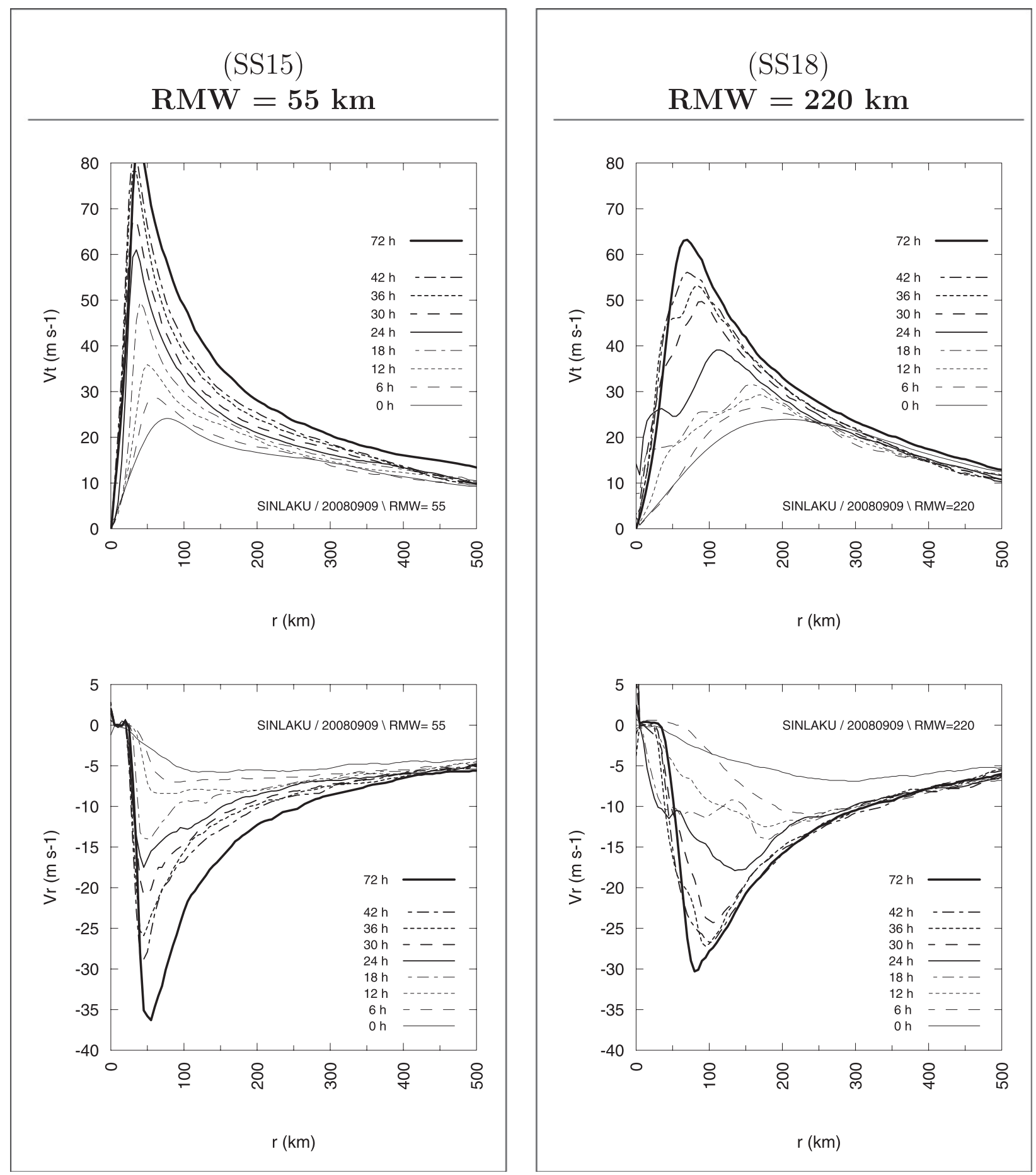

FIG. 13. Radial profiles of azimuthally averaged (top) tangential wind and (bottom) radial wind speed at the $0.975 \sigma$ level for (left) SS15 and (right) SS18 forecasts, at 6-h intervals.

While waiting for such techniques to be available, for current situations when the microwave imagery exhibit convective bands surrounding the circulation at outer radii (as was observed for Sinlaku), we recommend to initialize a TC-LAPS forecast with a RMW value corresponding to the observed PBC, or at least include such simulations in ensemble predictions. Of course, further experiments need to be carried out on other TCs that underwent rapid intensification to extend the hypothesis and understand the operative "interior eyewall formation." 
(a)

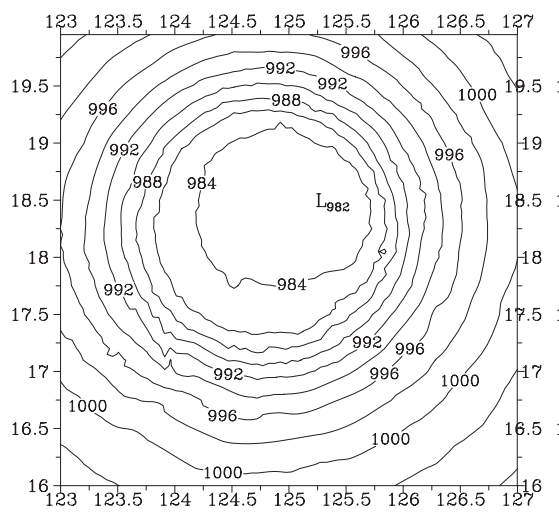

(d) (b) PRIOR

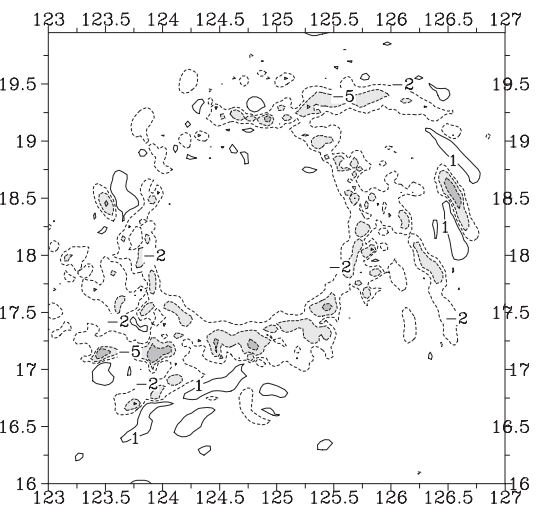

(e) DURING (c)

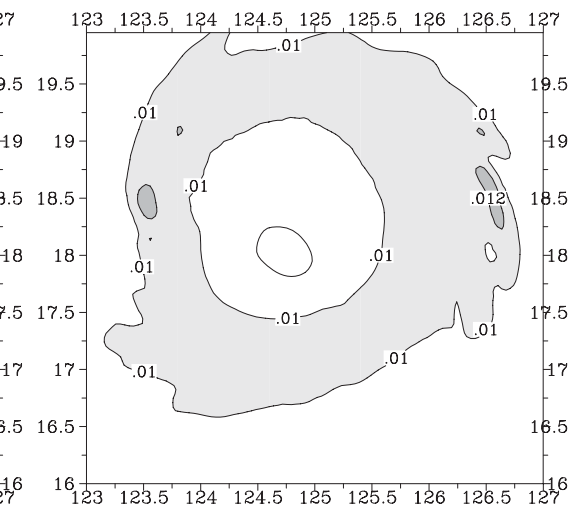

(f)

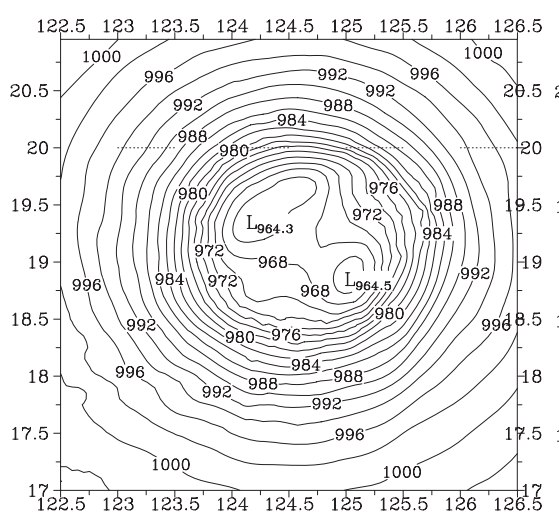

$(\mathrm{g})$

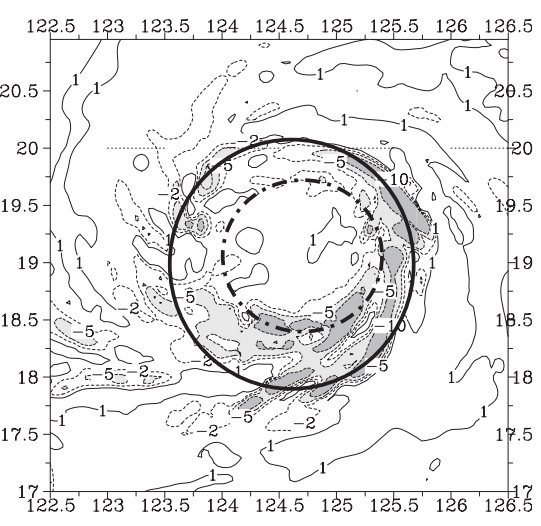

(h) AFTER

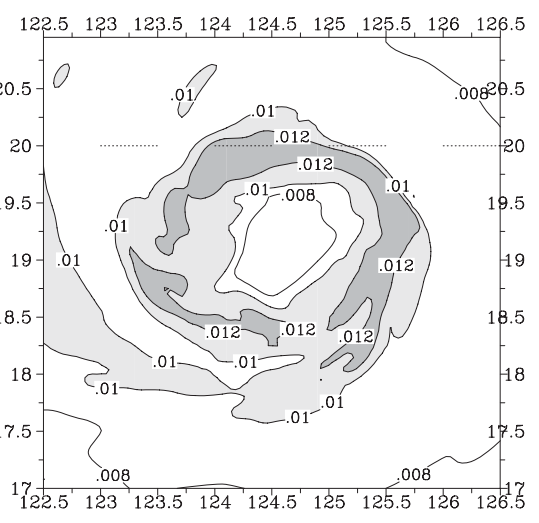

(i)

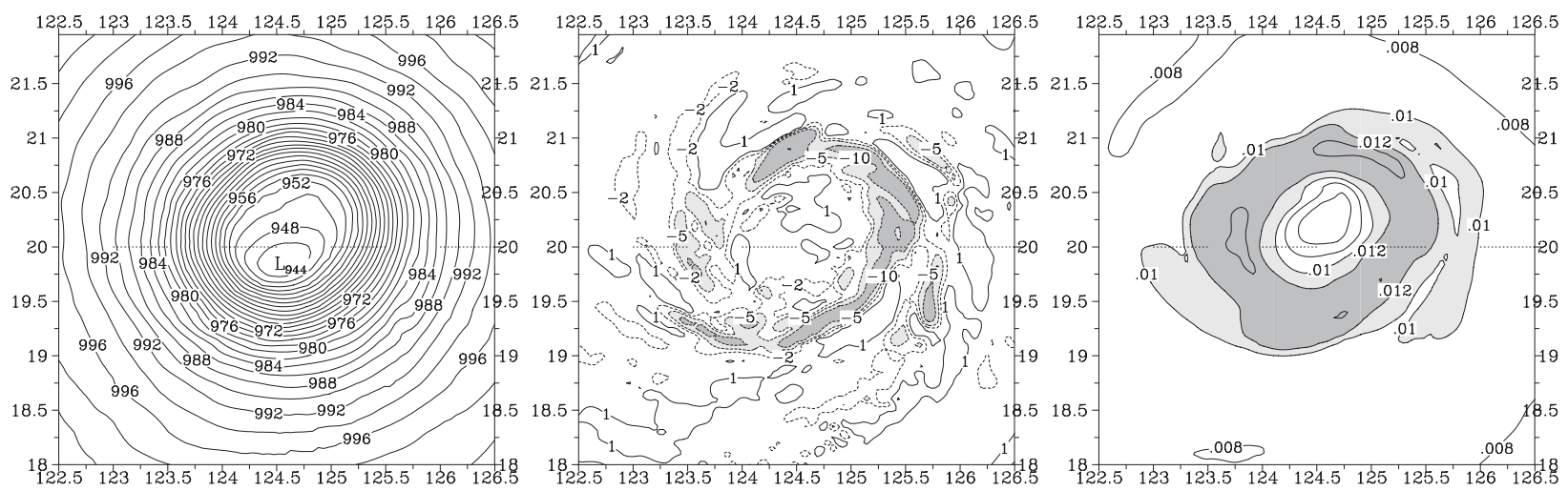

FIG. 14. Forecast fields at (a)-(c) 12, (d)-(f) 21, and (g)-(i) $30 \mathrm{~h}$ into the SS18 simulation (RMW = $220 \mathrm{~km}$ ): (left) surface pressure (hPa), (middle) 700-hPa vertical motion omega, and (right) 700-hPa mixing ratio. The times selected correspond to the three phases prior to, during, and after IEF. In (e), the forming inner eyewall is highlighted with a dashed circle inside the outer primary eyewall (solid circle). Contours for omega are 1.0 (solid) and $-2.0,-5.0$, and -10.0 (dotted) $\mathrm{Pa} \mathrm{s}^{-1}$; light (dark) shading indicates values between -5.0 and $-10.0(<-10.0)$ $\mathrm{Pa} \mathrm{s}^{-1}$. Light (dark) shading is also used for mixing ratio values between 0.01 and $0.012(>0.012) \mathrm{kg} \mathrm{kg}^{-1}$.

\section{Summary and conclusions}

This study addresses the potential impact of initial vortex structure on TC motion and intensity in a highresolution, full physics model, and discusses the possible underlying mechanisms. A case study of Typhoon Sinlaku at the onset of rapid intensification is used as an illustrative example. Aircraft observations indicate that the structure of the weak storm at the onset of RI was not clearly defined. This created uncertainties with 
(a)

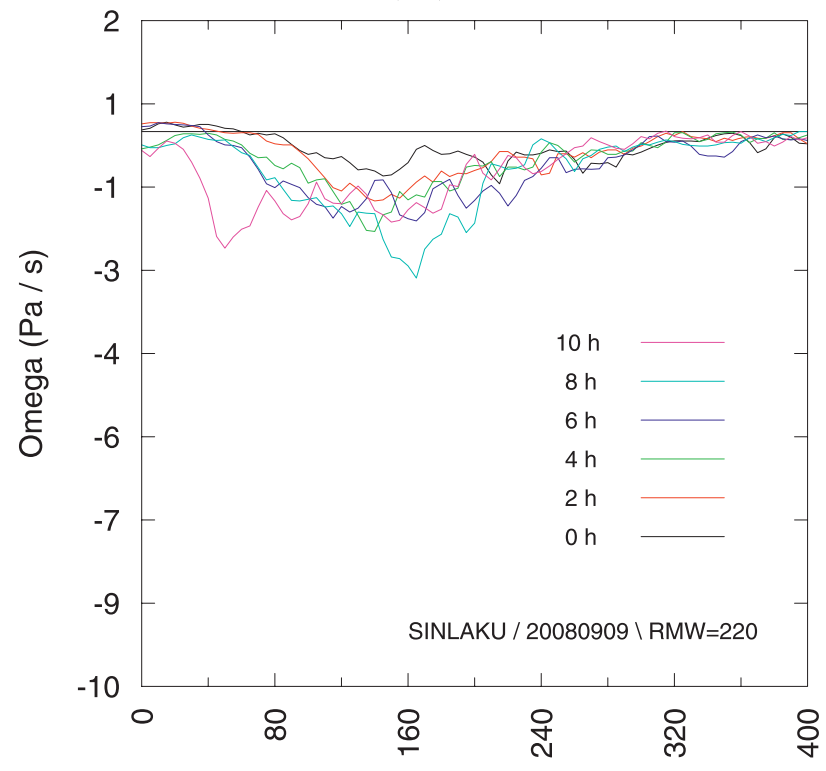

$r(\mathrm{~km})$

(c)

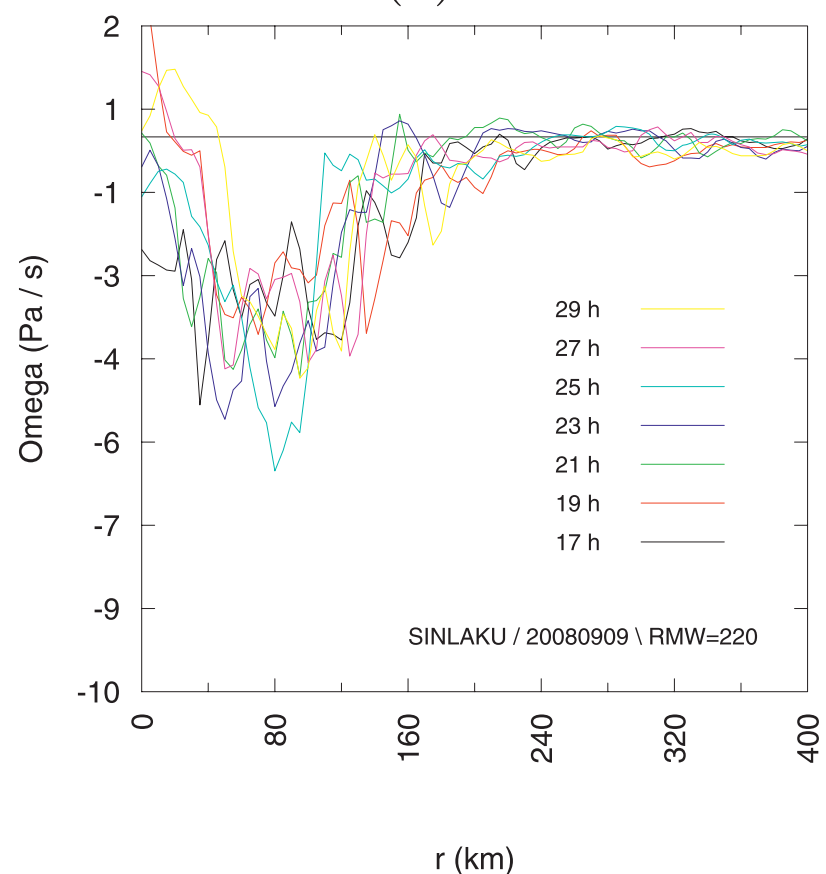

(b)

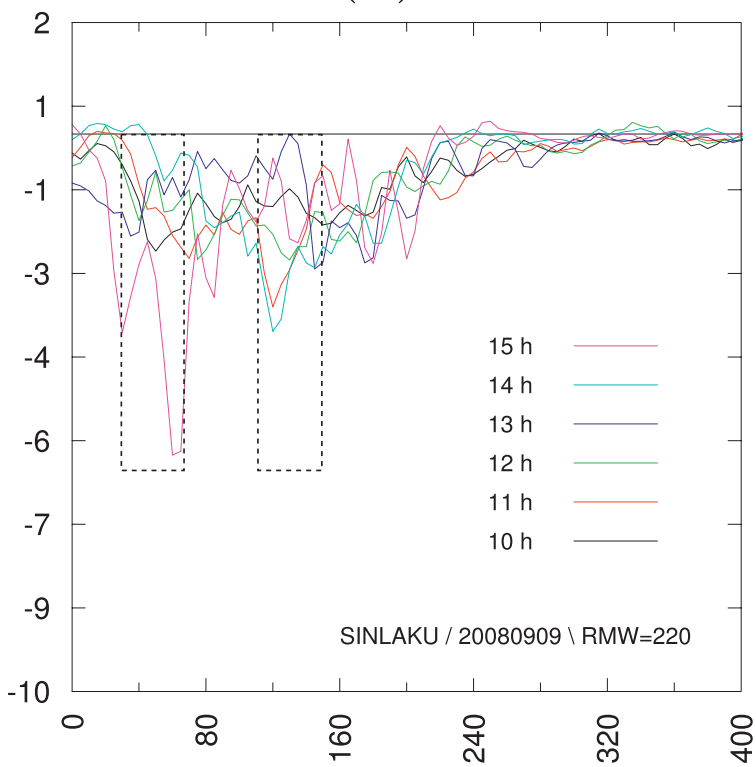

$r(\mathrm{~km})$

(d)

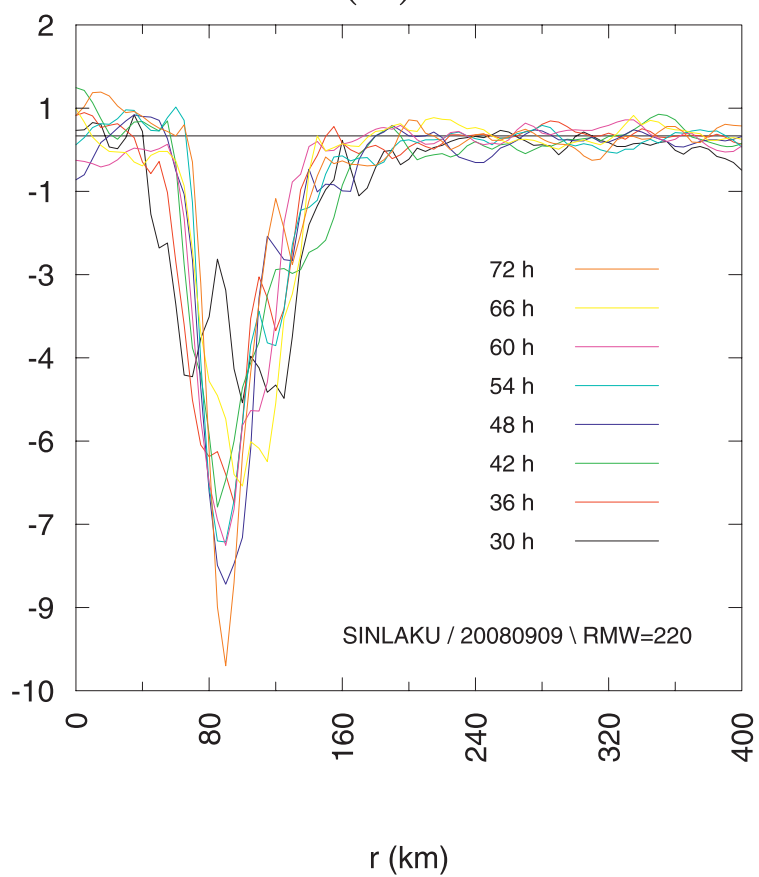

FIG. 15. (a)-(d) Radial profiles of mean omega $\left(\mathrm{Pa} \mathrm{s}^{-1}\right)$ at the $0.975 \sigma$ level at various lead times into the SS18 forecast $(\mathrm{RMW}=$ $220 \mathrm{~km}$ ). Omega is azimuthally averaged at each radii. Rectangles in (b) highlight the two regions of ascent that are present in the boundary layer, the outer one being located around the RMW. These two regions are still evident in (c) although closer to each other; they eventually merge in (d). 
estimates of storm structure and size parameters such as the RMW. Microwave images further showed a subsequent eyewall formation at small radii inside of a primary band of convection (PBC) present at outer radii.

An interesting aspect of Sinlaku's evolution was the departure of its motion from the south-southwesterly steering flow once it had intensified. This departure suggested the presence and importance of beta propagation during the time when the steering flow weakened. A dynamical analysis of the analyzed flow confirmed the presence and importance of $\beta$ gyres developing near the large storm. It is concluded that the motion of the storm was influenced partly but significantly by the $\beta$ effect, as environmental steering weakened and the structure and size of the vortex changed.

A set of numerical experiments was designed with the full-physics version of TC-LAPS to assess the sensitivity of motion and intensity prediction to initial storm structure. Of particular interest was the role played by the outer band of convection on the storm structure, track, and intensification. The PBC could well have been associated with an outer wind maximum and was represented in initial conditions using a large RMW value. The high-resolution simulation using this initial structure provided improved verification of both track (after $36 \mathrm{~h}$ ) and intensity. Two major results were obtained. First, TC-LAPS was able to account for the observed beta propagation after $36 \mathrm{~h}$. The northwestward contribution was more important when the region of maximum winds specified at the initial time was large, consistent with stronger $\beta$ gyres for large storms, as suggested by barotropic studies (e.g., Chan and Williams 1987). It is possible that the remaining error for track prediction may have been influenced by errors in the large-scale environment (similar to Komaromi et al. 2011) or by "upscale error growth," but such influences have not yet been detected during the times discussed here. Second, a suggestion of interior eyewall formation was produced in $5-\mathrm{km}$ resolution experiments when the vortex was initialized with a large initial RMW (corresponding to the primary outer band of convection). Conversely, the vortex initialized with a small RMW corresponding to the developing eyewall moved too far eastward and overintensified. The reason for the different evolution of the large RMW simulation is still somewhat uncertain. It may represent the dynamics of eyewall formation within a PBC (or an outer wind maximum region) for weak storms that undergo rapid intensification.

Although the results presented here are based on a case study of a particular storm, we believe they point us in a fruitful direction for understanding vortex structure and intensity changes. Evidence has been presented that storm size and wind distribution can, on occasions be critical influences on storm motion, and in the pathway to RI. Future studies are needed to confirm the robustness of such results using ensemble experiments since Zhang and Sippel (2009) showed that very small variations in the model state, practically within the noise of analyses, can result in different routes to tropical cyclogenesis. Further work is also planned to understand (i) how IEF can arise in a large storm, (ii) the influence of model resolution, (iii) the role of outer convective bands and vortex Rossby waves in assisting convection to develop near the storm center, and (iv) whether this phenomenon can be validated with high temporal sampling of cloud banding from satellite data. Another significant challenge for numerical prediction is initializing strong TCs with primary and secondary wind maxima, as may have occurred during Sinlaku's eyewall replacement cycle, and accurately predicting the subsequent intensity/structure evolution (e.g., Wu et al. 2012). This is clearly a question to be resolved by future research, as we recommend the investigation of new bogus schemes that would be able to take into account several regions of maximum winds/convection.

Acknowledgments. The authors thank the Centre for Australian Weather and Climate Research for generously supplying computing facilities for the completion of this project, as well as the TCS08 field experiment for their data. Thanks are extended to Dr. Chi Mai Nguyen for her helpful discussions on section 5, and to Dr. Harry Weber for his advice on beta-effect diagnostics. Important comments by the anonymous reviewers and Drs. Chun-Chieh Wu, Jason Sippel, and Matthieu Plu greatly improved the study and the presentation.

\section{REFERENCES}

Bender, M. A., 1997: The effect of relative flow on the asymmetric structure in the interior of hurricanes. J. Atmos. Sci., 54, 703724.

— R. J. Ross, R. E. Tuleya, and Y. Kurihara, 1993: Improvements in tropical cyclone track and intensity forecasts using the GFDL Initialization System. Mon. Wea. Rev., 121, 20462061.

Cao, Y., R. G. Fovell, and K. L. Corbosiero, 2011: Tropical cyclone track and structure sensitivity to initialization in idealized simulations: A preliminary study. Terr. Atmos. Oceanic Sci., 22, 559-578.

Carr, L. E., and R. L. Elsberry, 1992: Analytical tropical cyclone asymmetric circulation for barotropic model initial conditions. Mon. Wea. Rev., 120, 644-652.

— and - 1997: Models of tropical cyclone wind distribution and beta-effect propagation for application to tropical cyclone track forecasting. Mon. Wea. Rev., 125, 3190-3209.

Chan, J. C.-L., and R. T. Williams, 1987: Analytical and numerical studies of the beta-effect in tropical cyclone motion. Part I: Zero mean flow. J. Atmos. Sci., 44, 1257-1265. 
Chen, T.-C., S.-Y. Wang, M.-C. Yen, and A. J. Clark, 2008: Are tropical cyclones less effectively formed by easterly waves in the western North Pacific than in the North Atlantic? Mon. Wea. Rev., 136, 4527-4540.

Davidson, N. E., and H. C. Weber, 2000: The BMRC HighResolution Tropical Cyclone Prediction System: TC-LAPS. Mon. Wea. Rev., 128, 1245-1265.

— and initialization for hurricane prediction. Part II: Numerical simulations of track, structure and intensity. Meteor. Atmos. Phys., 117, 25-45.

_ J. Wadsley, K. Puri, K. Kurihara, and M. Ueno, 1993: Implementation of the JMA typhoon bogus in the BMRC tropical prediction system. J. Meteor. Soc. Japan, 71, 437-467.

_ L. J. Rikus, R. A. Dare, C. I. W. Tingwell, and H. C. Weber, 2006: Validation of TC-LAPS structure forecasts of some significant 2004-2005 U.S. hurricanes. Preprints, 27th Conf. on Hurricanes and Tropical Meteorology, Monterey, CA, Amer. Meteor. Soc., P14A.2. [Available online at https://ams.confex. com/ams/27Hurricanes/webprogram/Paper107795.html.]

— C. M. Nguyen, and M. Reeder, 2008: Downstream development during the rapid intensification of Hurricanes Opal and Katrina: The distant trough interaction problem. Preprints, 28th Conf. on Hurricanes and Tropical Meteorology, Orlando, FL, Amer. Meteor. Soc., P9B.4. [Available online at https://ams.confex.com/ams/28Hurricanes/techprogram/paper_ 138060.htm.]

Dvorak, V. F., 1975: Tropical cyclone intensity analysis and forecasting from satellite imagery. Mon. Wea. Rev., 103, 420430.

Elsberry, R. L., P. A. Harr, R. Ferek, S. Chang, and D. Eleuterio, 2008: Tropical Cyclone Structure (TCS08) Field Experiment in the western North Pacific during 2008. Preprints, 28th Conf. on Hurricanes and Tropical Meteorology, Orlando, FL, Amer. Meteor. Soc., P7C.6. [Available online at https://ams.confex. com/ams/28Hurricanes/techprogram/paper_138469.htm.]

Emanuel, K. A., 1986: An air-sea interaction theory for tropical cyclones. Part I: Steady-state maintenance. J. Atmos. Sci., 43, 585-604.

Fiorino, M., and R. L. Elsberry, 1989: Contributions to tropical cyclone motion by small, medium and large scales in the initial vortex. Mon. Wea. Rev., 117, 721-727.

Franklin, J. L., cited 2008: National Hurricane Center forecast verification report. [Available online at http://www.nhc.noaa. gov/verification.]

— , S. E. Feuer, J. Kaplan, and S. D. Aberson, 1996: Tropical cyclone motion and surrounding flow relationships: Searching for beta gyres in omega dropwindsonde datasets. Mon. Wea. Rev., 124, 64-84.

Fujita, T., 1952: Pressure distribution within a typhoon. Geophys. Mag., 23, 437-451.

Hanley, D., J. Molinari, and D. Keyser, 2001: A compositive study of the interactions between tropical cyclones and uppertropospheric troughs. Mon. Wea. Rev., 129, 2570-2584.

Hausman, S. A., K. V. Ooyama, and W. H. Schubert, 2006: Potential vorticity structure of simulated hurricanes. J. Atmos. Sci., 63, 87-108.

Havel, P. J., 2009: Surface wind field analyses of tropical cyclones during TCS-08: Relative impacts of aircraft and remotelysensed observations. M.S. thesis, Department of Meteorology and Physical Oceanography, Naval Postgraduate School, 99 pp. [Available online at http://edocs.nps.edu/npspubs/scholarly/ theses/2009/Sep/09Sep_Havel.pdf.]
Hendricks, E. A., W. H. Schubert, R. K. Taft, H. Wang, and J. P. Kossin, 2009: Life cycles of hurricane-like vorticity rings. J. Atmos. Sci., 66, 705-722.

Holland, G. J., 1983: Tropical cyclone motion: Environmental interaction plus a beta effect. J. Atmos. Sci., 40, 328-342.

Huang, Y.-H., M. T. Montgomery, and C.-C. Wu, 2012: Concentric eyewall formation in Typhoon Sinlaku (2008). Part II: Axisymmetric dynamical processes. J. Atmos. Sci., 69, 662-674.

Kaplan, J., and M. DeMaria, 2003: Large-scale characteristics of rapidly intensifying tropical cyclones in the North Atlantic basin. Wea. Forecasting, 18, 1093-1108.

Kieper, M. E., 2008: A technique for anticipating initial rapid increases in intensity in tropical cyclones, using $37 \mathrm{GHz}$ microwave imagery. Preprints, 28th Conf. on Hurricanes and Tropical Meteorology, Orlando, FL, Amer. Meteor. Soc., P2B.15. [Available online at https://ams.confex.com/ams/28Hurricanes/ webprogram/Paper140605.html.]

Knaff, J. A., and M. DeMaria, 2006: A multi-platform satellite tropical cyclone wind analysis system. Preprints, 14th Conf. on Satellite Meteorology and Oceanography, Atlanta, GA, Amer. Meteor. Soc., P4.9. [Available online at https://ams.confex. com/ams/Annual2006/webprogram/Paper99945.html.]

Knapp, K. R., M. C. Kruk, D. H. Levinson, H. J. Diamond, and C. J. Neumann, 2010: The International Best Track Archive for Climate Stewardship (IBTrACS): Unifying tropical cyclone best track data. Bull. Amer. Meteor. Soc., 91, 363-376.

Komaromi, W. A., S. J. Majumdar, and E. D. Rappin, 2011: Diagnosing initial condition sensitivity of Typhoon Sinlaku (2008) and Hurricane Ike (2008). Mon. Wea. Rev., 139, 32243324.

Kossin, J. P., and W. H. Schubert, 2001: Mesovortices, polygonal flow patterns, and rapid pressure falls in hurricane-like vortices. J. Atmos. Sci., 58, 2196-2209.

Kurihara, Y., M. A. Bender, and R. J. Ross, 1993: An initialization scheme of hurricane models by vortex specification. Mon. Wea. Rev., 121, 2030-2045.

,,-- R. E. Tuleya, and R. J. Ross, 1995: Improvements in the GFDL Hurricane Prediction System. Mon. Wea. Rev., 123, 2791-2801.

Kwon, H. J., S. Won, M. Ahn, A. Suh, and H. Chung, 2002: GFDLtype typhoon initialization in MM5. Mon. Wea. Rev., 130, 2966-2974.

Lee, C.-S., K. K. W. Cheung, W.-T. Fang, and R. L. Elsberry, 2010: Initial maintenance of tropical cyclone size in the western North Pacific. Mon. Wea. Rev., 138, 3207-3223.

Lin, I. I., C. C. Wu, K. A. Emanuel, I. H. Lee, C. R. Wu, and I. Pun, 2005: The interaction of Supertyphoon Maemi (2003) with a warm ocean eddy. Mon. Wea. Rev., 133, 2635-2649.

Liu, H., and J. Li, 2010: An improvement in forecasting rapid intensification of Typhoon Sinlaku (2008) using clear-sky full spatial resolution advanced IR soundings. J. Appl. Meteor. Climatol., 49, 821-827.

Ma, Y., M. Kafatos, and N. E. Davidson, 2012: Surface pressure profiles, vortex structure and initialization for hurricane prediction. Part I: Analysis of observed and synthetic structures. Meteor. Atmos. Phys., 117, 5-23.

Molinari, J., and D. Vollaro, 1989: External influences on hurricane intensity. Part I: Outflow layer eddy momentum fluxes. J. Atmos. Sci., 46, 1093-1105.

Montgomery, M. T., and R. J. Kallenbach, 1997: A theory of vortex Rossby waves and its application to spiral bands and intensity changes in hurricanes. Quart. J. Roy. Meteor. Soc., 123, 435465 . 
— M. E. Nicholls, T. A. Cram, and A. B. Saunders, 2006: A vortical hot tower route to tropical cyclogenesis. J. Atmos. Sci., 63, 355-386.

Montroty, R., F. Rabier, S. Westrelin, G. Faure, and N. Viltard, 2008: Impact of wind bogus and cloud- and rain-affected SSM/I data on tropical cyclone analyses and forecasts. Quart. J. Roy. Meteor. Soc., 134, 1673-1699.

Mueller, K. J., M. DeMaria, J. A. Knaff, J. P. Kossin, and T. V. Haar, 2006: Objective estimation of tropical cyclone wind structure from infrared satellite data. Wea. Forecasting, 21, 990-1005.

Nguyen, C. M., M. J. Reeder, N. E. Davidson, M. T. Montgomery, and R. K. Smith, 2011: Vacillations cycles during the intensification of Hurricane Katrina. Quart. J. Roy. Meteor. Soc., 137, 829-844.

Persing, J., and M. T. Montgomery, 2003: Hurricane superintensity. J. Atmos. Sci., 60, 2349-2371.

$\mathrm{Pu}, \mathrm{Z} . \mathrm{X}$., and S. A. Braun, 2001: Evaluation of bogus vortex techniques with four-dimensional variational data assimilation. Mon. Wea. Rev., 129, 2023-2039.

Puri, K., and Coauthors, 2010: Preliminary results from numerical weather prediction implementation of ACCESS. CAWCR Res. Lett., 5, 15-22. [Available online at http://www.cawcr.gov. $\mathrm{au} /$ publications/researchletters/CAWCR_Research_Letters_5. pdf.]

Reeder, M. J., R. K. Smith, and S. J. Lord, 1991: The detection of flow asymmetries in the tropical cyclone environment. Mon. Wea. Rev., 119, 848-855.

Ritchie, E. A., and R. L. Elsberry, 2007: Simulations of the extratropical transition of tropical cyclones: Phasing between the upper-level trough and tropical systems. Mon. Wea. Rev., 135, 862-876.

Samsury, C. E., and E. J. Zipser, 1995: Secondary wind maxima in hurricanes: Airflow and relationship to rainbands. Mon. Wea. Rev., 123, 3502-3517.

Schloemer, R. W., 1954: Analysis and synthesis of hurricane wind patterns over Lake Okeechobee, FL. Hydrometeorological Rep. 31, 49 pp.

Schubert, W. H., M. T. Montgomery, R. K. Taft, T. A. Guinn, S. R. Fulton, J. P. Kossin, and J. P. Edwards, 1999: Polygonal eyewalls, asymmetric eye contraction, and potential vorticity mixing in hurricanes. J. Atmos. Sci., 56, 1197-1223.

Shapiro, L. J., and H. E. Willoughby, 1982: The response of balanced hurricanes to local sources of heat and momentum. J. Atmos. Sci., 39, 378-394.

Shay, L. K., G. J. Goni, and P. G. Black, 2000: Effects of a warm oceanic feature on Hurricane Opal. Mon. Wea. Rev., 128, 1366-1383.
Van Sang, N., R. K. Smith, and M. T. Montgomery, 2008: Tropicalcyclone intensification and predictability in three dimensions. Quart. J. Roy. Meteor. Soc., 134, 563-582.

Wang, Y., 2002: Vortex Rossby waves in a numerically simulated tropical cyclone. Part II: The role in tropical cyclone structure and intensity changes. J. Atmos. Sci., 59, 1239-1262.

Weber, H. C., 2006: On the pressure-wind relationship in tropical cyclones. Preprints, 27th Conf. on Hurricanes and Tropical Meteorology, Monterey, CA, Amer. Meteor. Soc., P14A.6. [Available online at https://ams.confex.com/ams/27Hurricanes/ webprogram/Paper107849.html.]

_ , and R. K. Smith, 1995: Data sparsity and the tropical-cyclone analysis and prediction problem: Some simulation experiments with a barotropic numerical model. Quart. J. Roy. Meteor. Soc., 121, 631-654.

Willoughby, H. E., 1990: Temporal changes of the primary circulation in tropical cyclones. J. Atmos. Sci., 47, 242-264.

_ J. A. Clos, and M. G. Shoreibah, 1982: Concentric eyewalls, secondary wind maxima, and the evolution of the hurricane vortex. J. Atmos. Sci., 39, 395-411.

Wu, C.-C., K.-H. Chou, Y. Wang, and Y.-H. Kuo, 2006: Tropical cyclone initialization and prediction based on fourdimensional variational data assimilation. J. Atmos. Sci., 63, 2383-2395.

—, G.-Y. Lien, J.-H. Chen, and F. Zhang, 2010: Assimilation of tropical cyclone track and structure based on the Ensemble Kalman Filter (EnKF). J. Atmos. Sci., 67, 38063822.

—, Y.-H. Huang, and G.-Y. Lien, 2012: Concentric eyewall formation in Typhoon Sinlaku (2008). Part I: Assimilation of T-PARC data based on the Ensemble Kalman Filter (EnKF). Mon. Wea. Rev., 140, 506-527.

Xiao, Q., X. Zou, and Y.-H. Kuo, 2000: Incorporating the SSM/IDerived Precipitable Water and Rainfall Rate into a numerical model: A case study for the ERICA IOP-4 Cyclone. Mon. Wea. Rev., 128, 87-108.

$\mathrm{Xu}$, J., and Y. Wang, 2010: Sensitivity of the simulated tropical cyclone inner-core size to initial vortex size. Mon. Wea. Rev., 138, 4135-4157.

Zhang, F., and J. A. Sippel, 2009: Effects of moist convection on hurricane predictability. J. Atmos. Sci., 66, 1944-1961.

Zhu, T., D.-L. Zhang, and F. Weng, 2002: Impact of the Advanced Microwave Sounding Unit measurements on hurricane prediction. Mon. Wea. Rev., 130, 2416-2432.

Zou, X., and Q. Xiao, 2000: Studies on the initialization and simulation of a mature hurricane using a variational bogus data assimilation scheme. J. Atmos. Sci., 57, 836-860. 